CARDIOVASCULAR POPULATION

by

Mona Siadat-Khoo

BScN, Ryerson University, Canada, 2015

\author{
A thesis \\ presented to Ryerson University \\ in partial fulfillment of the \\ requirements for the degree of \\ Master of Nursing \\ in the Program of \\ Nursing
}

Toronto, Ontario, Canada, 2019

(C) Mona Siadat-Khoo 2019 


\section{AUTHOR'S DECLARATION}

I hereby declare that I am the sole author of this thesis. This is a true copy of the thesis, including any required final revisions, as accepted by my examiners.

I authorize Ryerson University to lend this thesis to other institutions or individuals for the purpose of scholarly research.

I further authorize Ryerson University to reproduce this thesis by photocopying or by other means, in total or in part, at the request of other institutions or individuals for the purpose of scholarly research.

I understand that my thesis may be made electronically available to the public. 


\title{
EXAMINING CHRONIC INSOMNIA AND CARDIAC SYMPTOM EXPERIENCE IN THE CARDIOVASCULAR POPULATION
}

\author{
Mona Siadat-Khoo \\ Master of Nursing \\ Daphne Cockwell School of Nursing \\ Ryerson University, Toronto, 2019
}

\begin{abstract}
Background: Chronic insomnia affects $10-15 \%$ of the world population and is associated with development of cardiovascular diseases [CVD], which remain the second leading cause of death in Canada. CVD is associated with cardiac symptoms and decreased quality-of-life.

Purpose: To examine the experience of chronic insomnia, as well as its association with cardiac symptoms, in individuals with CVD.

Methodology: Secondary analysis with a descriptive correlational design, among two groups (CVD [n=33] and non-CVD [n=36]).

Results: Individuals with CVD experienced greater difficulty maintaining sleep ( $t=-2.69, p=.01$, $\mathrm{d}=.66$ ). In the CVD and non-CVD groups, insomnia severity and daytime sleepiness were positively and moderately associated with cardiac symptoms. In the CVD group, insomnia severity was negatively associated with dyspnea $(r=-.46, p=.01)$.

Implications: Future research can examine assessment of, and behavioural treatment for, chronic insomnia among differing cardiovascular populations to determine its effect on cardiac symptoms, morbidity, and mortality from cardiovascular diseases.
\end{abstract}




\section{ACKNOWLEDGEMENTS}

The original study from which this secondary analysis was derived was funded by the Canadian Institutes of Health Research. 


\section{DEDICATION}

Throughout the culmination of this process, there have been a number of individuals who in providing their guidance and unconditional support, deserve my unending gratitude.

To my thesis supervisor Dr. Joyal Miranda, for encouraging me to pursue the thesis stream, and for standing by me during each step of the way, I thank you. Your support, optimism, and reassurance were the backbone of this process.

To my committee members Dr. Suzanne Fredericks and Dr. Souraya Sidani, thank you kindly for the endless hours spent reviewing my work and providing assistance and feedback over the last two years. Your expertise was appreciated in every step of the way.

To my amazing brothers Reza and Hossein, your regular encouragement to advance through the hardships, to remember to acknowledge my own achievements, and to never forget to cherish the fun in this experience were appreciated immensely. More than just my brothers, you are my closest friends, and I value you more than you know.

Finally, to my wonderful parents, when I doubted my path, you provided me with your full support, and encouraged me to reach for happiness. I cannot thank you enough for providing us with every opportunity to succeed, as well as for your dedication to maintaining the closeness of this family bond. It wasn't always an easy road, but cheers to where we are today.

Without this community, I would not be where I am today. For each and every one of you, I am eternally grateful. 


\section{TABLE OF CONTENTS}

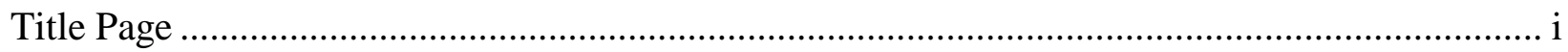

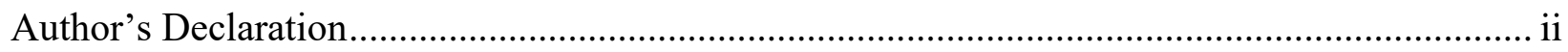

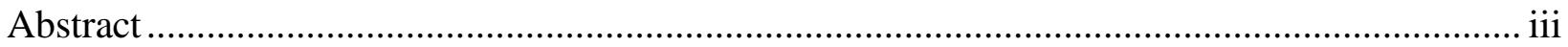

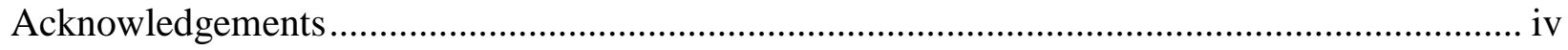

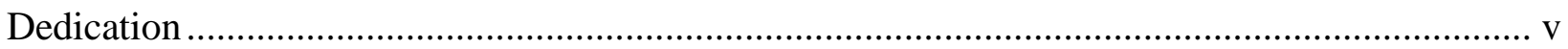

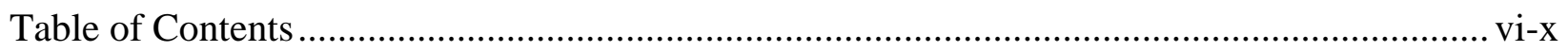

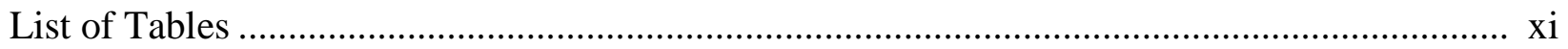

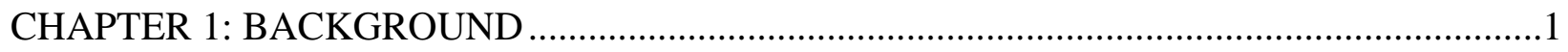

Research Problem......................................................................................................... 3

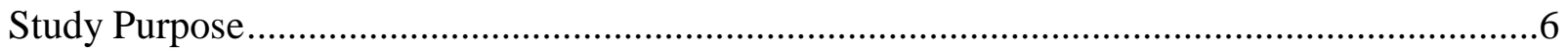

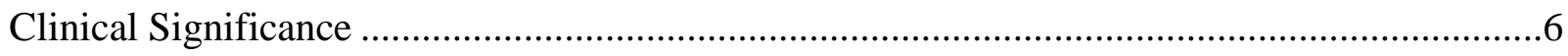

CHAPTER 2: LITERATURE REVIEW AND CONCEPTUAL FRAMEWORK ..........................

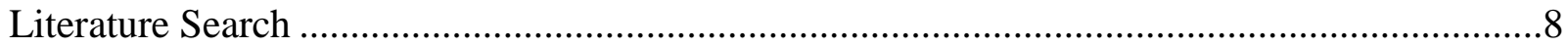

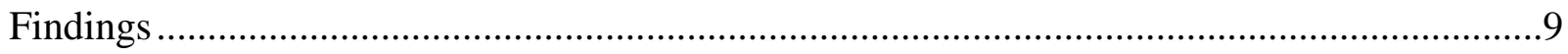

Insomnia and Cardiovascular Diseases (CVD) .............................................................

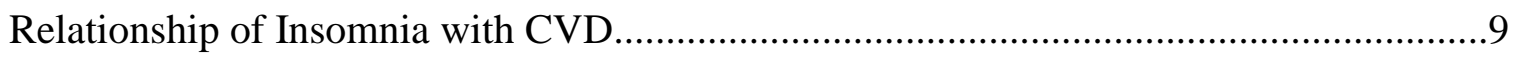

Concurrent CVD and Insomnia ………...............................................................10

Limitations of Literature .........................................................................................

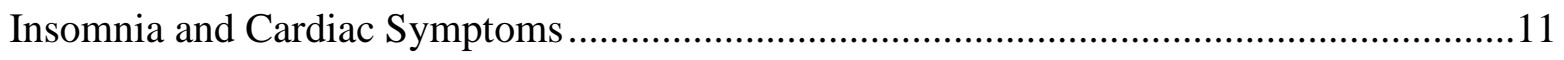


Limitations of Literature

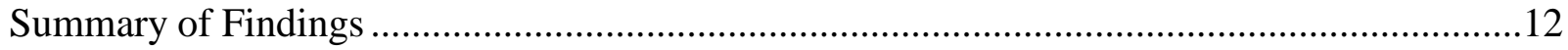

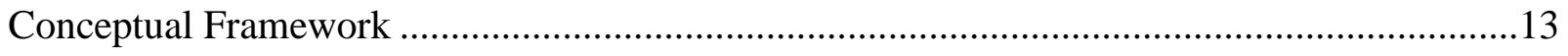

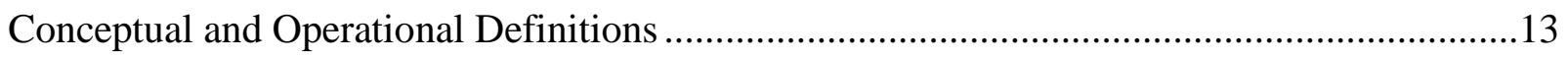

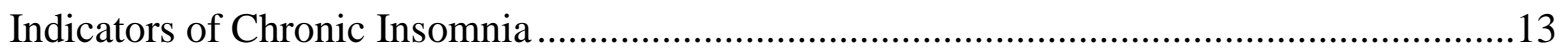

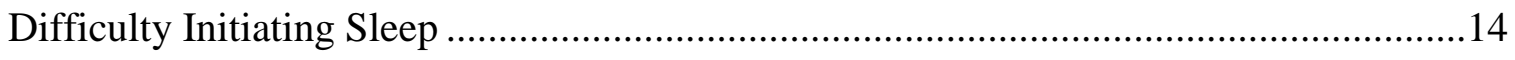

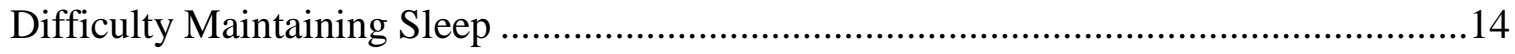

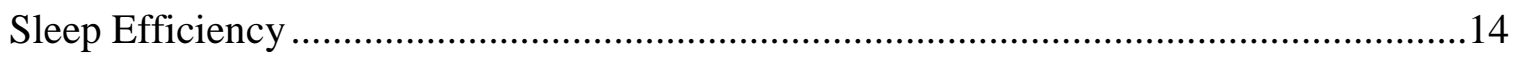

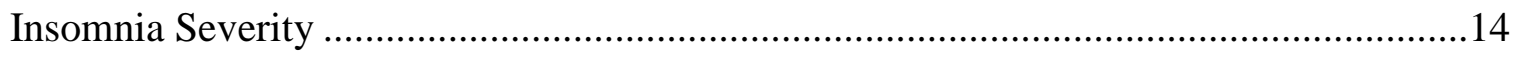

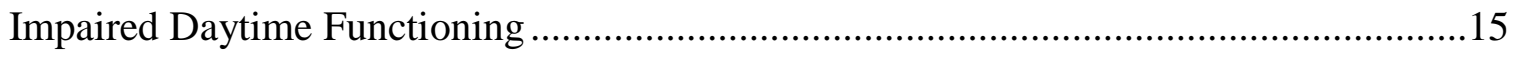

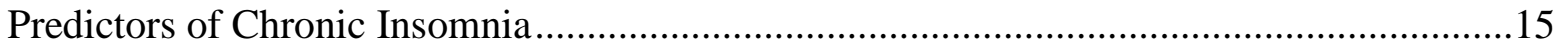

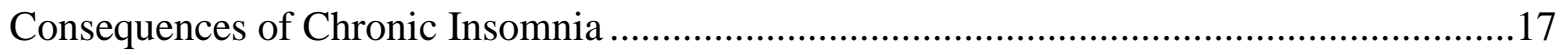

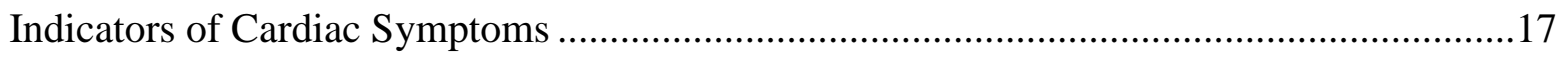

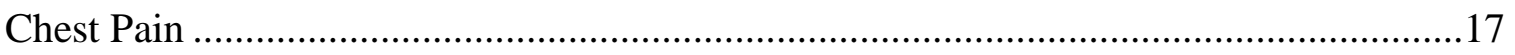

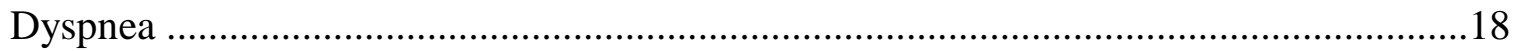

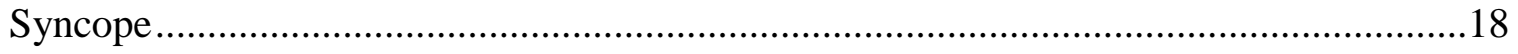

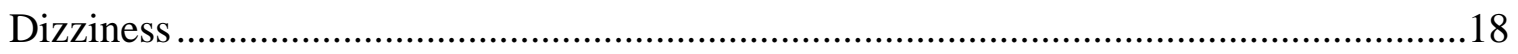

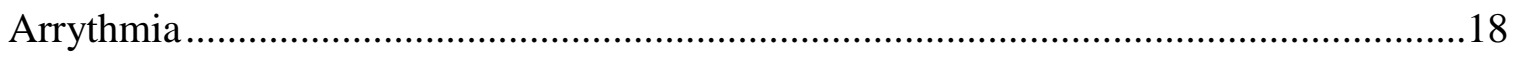

Predictors of Cardiac Symptoms .............................................................................. 19

Consequences of Cardiac Symptoms ….......................................................................19 
Relationships Under Study

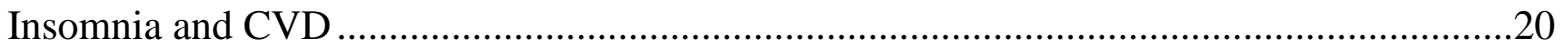

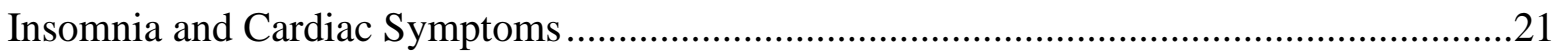

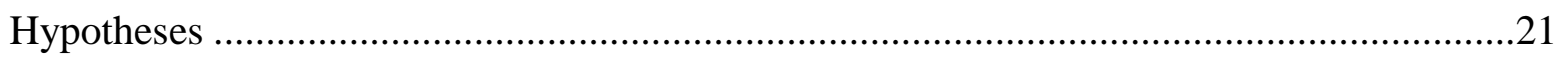

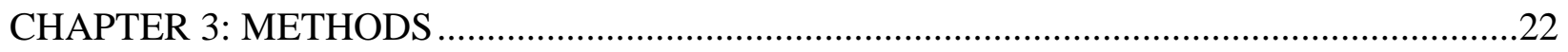

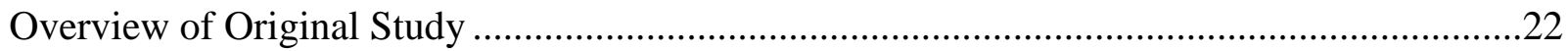

Design for Secondary Analysis .......................................................................................24

Sample

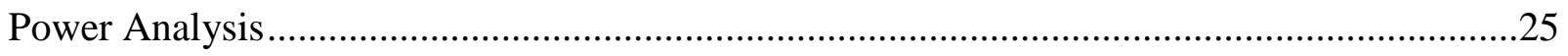

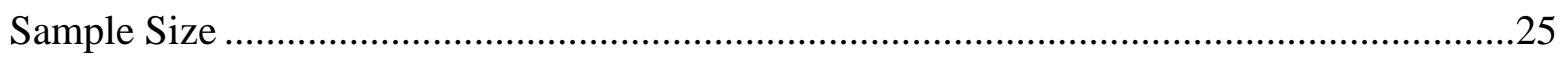

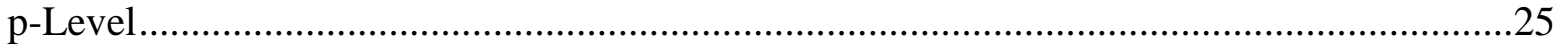

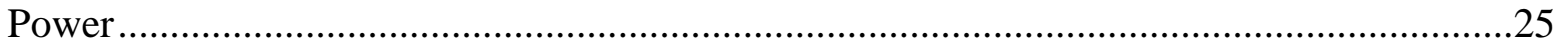

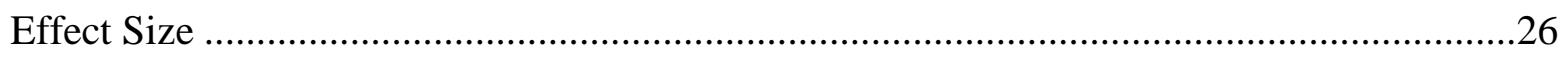

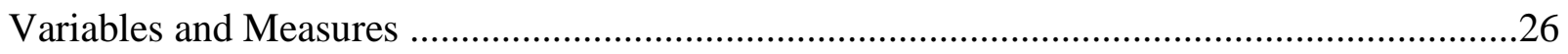

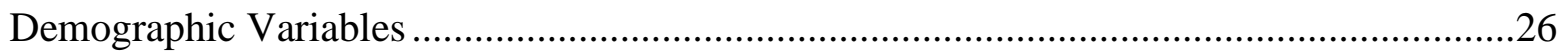

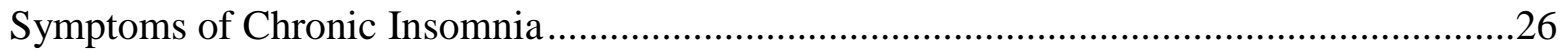

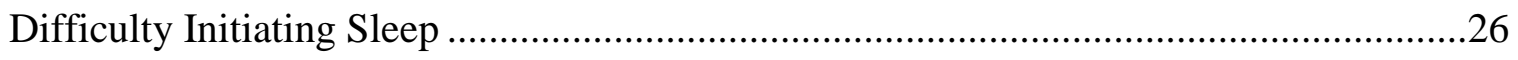

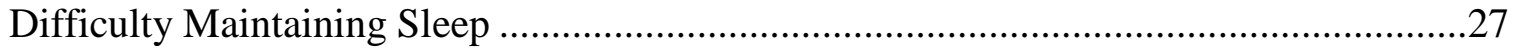

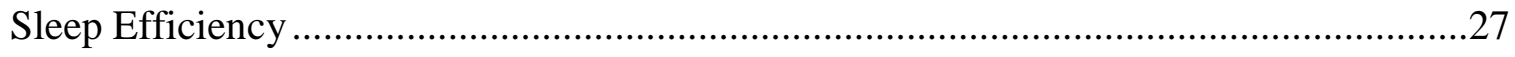

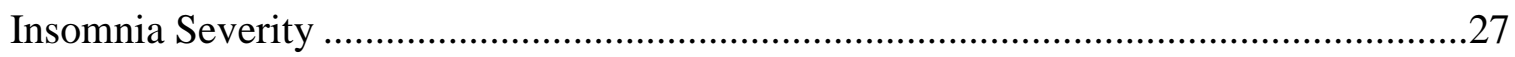


Impaired Daytime Functioning

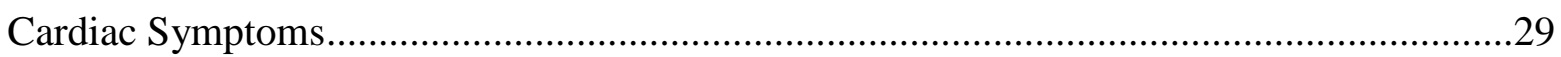

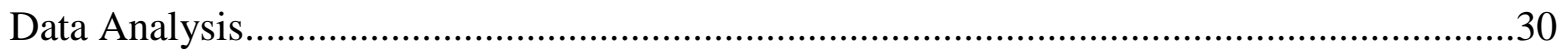

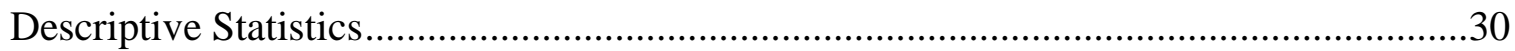

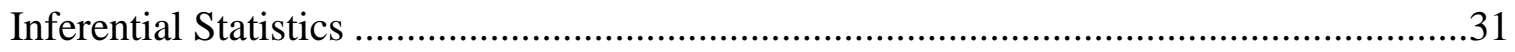

Differences in Presence of Chronic Insomnia Symptoms between Individuals with

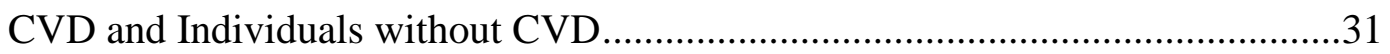

Relationships between Chronic Insomnia Symptoms and Cardiac Symptoms in Individuals with CVD and Individuals without CVD.....................................32

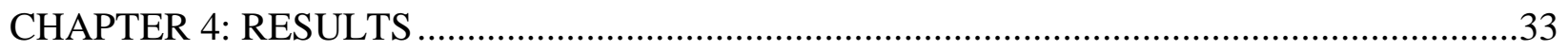

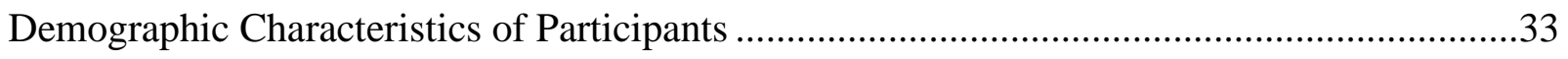

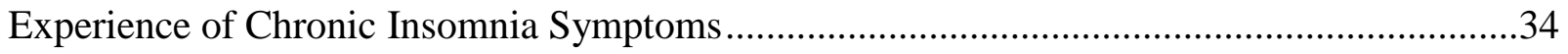

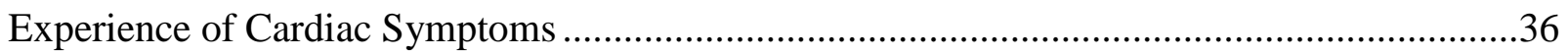

Differences between Individuals with CVD and Individuals without CVD on Chronic

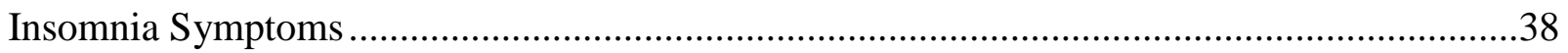

Relationships between Chronic Insomnia and Cardiac Symptoms Within Groups ..................39

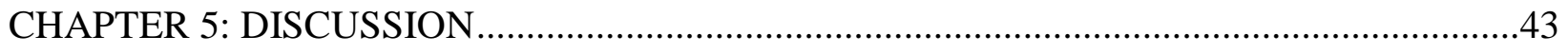

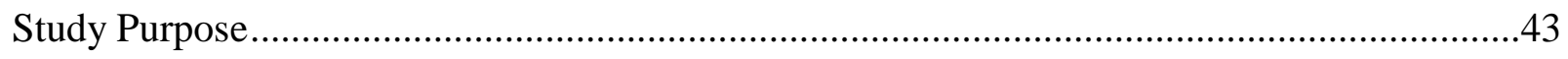

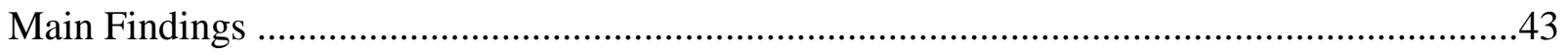


Hypothesis 1: Difference in Experience of Chronic Insomnia Symptoms between Individuals with CVD and Individuals without CVD

Hypothesis 2: Relationships between Chronic Insomnia Symptoms and Experience of

Cardiac Symptoms in Individuals with CVD and Individuals without CVD .45

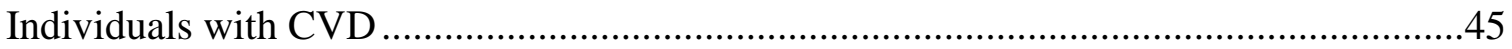

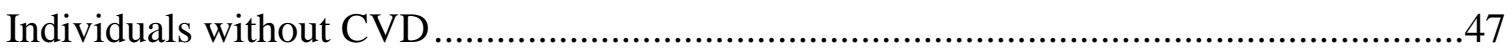

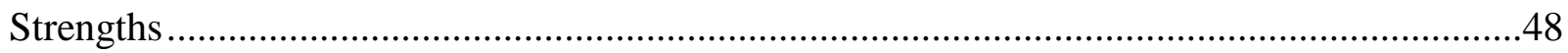

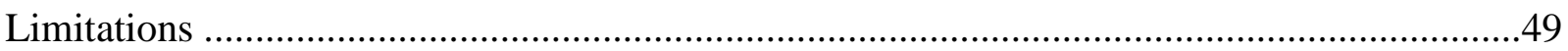

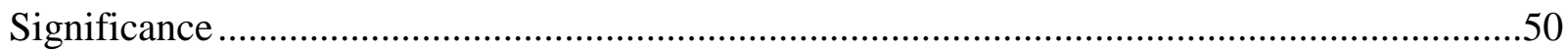

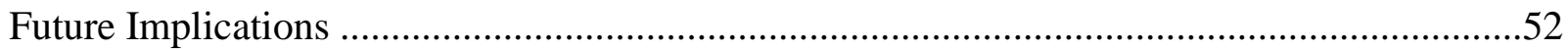

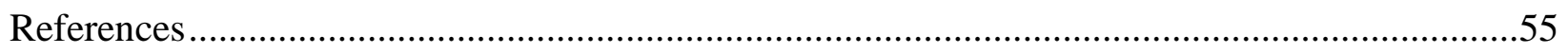




\section{LIST OF TABLES}

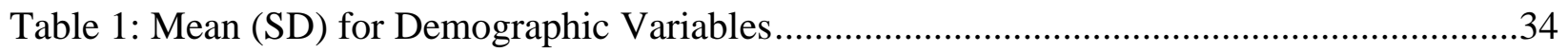

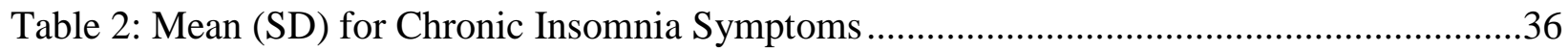

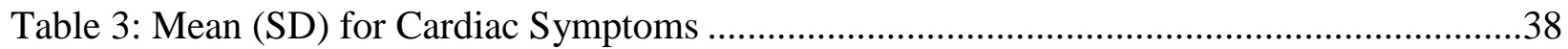

Table 4: Results of t-test for Chronic Insomnia Symptoms by CVD Status ...............................39

Table 5: Results of Pearson r Correlation for Chronic Insomnia Symptoms and Cardiac

Symptoms in Participants with No Cardiac Disease.............................................................

Table 6: Results of Pearson r Correlation for Chronic Insomnia Symptoms and Cardiac

Symptoms in Participants with Cardiac Disease ...............................................................42 


\section{Chapter 1: Background}

Chronic insomnia is a disorder manifested by self-reports of difficulty falling asleep, maintaining sleep, and/or early morning awakenings, associated with impaired daytime functioning, occurring at least three times a week for at least six consecutive weeks (Buysse, Rush, Reynolds, \& Reynolds, 2017; Ciano, King, Wright, Perlis, \& Sawyer, 2017; Maness \& Khan, 2015; Medalie \& Cifu, 2017). The central feature of chronic insomnia is a self-perceived dissatisfaction with sleep quality and quantity; it is identified not as being an experience of sleep deprivation, but rather occurs in the presence of ample sleeping opportunity (Buysse et al., 2017; Maness \& Khan, 2015). Chronic insomnia is more commonly found in women, the elderly, and in those with lower educational attainment (Chaput, Wong, \& Michaud, 2017; Ham, Kim, Lee, \& Choi, 2017; Maness \& Khan, 2015; Medalie \& Cifu, 2017; Sorscher, 2017).

Chronic insomnia, which affects approximately $10 \%$ to $15 \%$ of the population, is reported as the most common sleep disorder worldwide (Ciano et al., 2017; Winkelman, 2015). In Canada, $43 \%$ of adult men and $55 \%$ of adult women between the ages of 18-64 frequently reported insomnia symptoms of difficulty initiating and/or maintaining sleep (Chaput et al., 2017). In Canada, approximately $\$ 6.6$ billion is spent annually on both direct and indirect costs associated with insomnia (Garland et al., 2018). Direct costs include use of health care services including health care professional visits, home care, and prescription and non-prescription medications (Garland et al., 2018). Indirect costs are demonstrated socially through increased incidence of absenteeism and lost work productivity (Ciano et al., 2017; Garland et al., 2018; Hayley et al., 2015; Sorscher, 2017; Taylor, Bilan, Tsytsyna, \& Mandel, 2017), as well as workplace and fatal injuries (Hayley et al., 2015; Laugsand, Strand, Vatten, Janszky, \& Bjørngaard, 2014; Maness \& Khan, 2015; Shahly, Berglund, \& Coulouvrat, 2012; Sorscher, 
2017). On an individual level, chronic insomnia is associated with the experience of cognitive difficulties associated with memory, concentration, irritability, and confusion (Maness \& Khan, 2015, Sorscher, 2017) as well as limitations in the ability to engage in activities of daily living (Tessaro \& Navarro-Peternella, 2015), and decreased quality of life (Ciano et al., 2017; Maness \& Khan, 2015; Tessaro \& Navarro-Peternella, 2015).

Chronic insomnia also increases the risk of developing cardiovascular diseases, regardless of the presence of risk factors such as smoking, increased age, and lower levels of education (Hoevenaar-Blom, Spijkerman, Kromhout, van den Berg, \& Verschuren, 2011; King et al., 2008; Laugsand, Vatten, Platou, \& Janszky, 2011; Redeker et al., 2010). Hoevenaar-Blom and colleagues (2011) noted that individuals with poor sleep quality associated with chronic insomnia are at a $63 \%$ increased risk for the development of cardiovascular diseases. When looking at post-menopausal women, Sands-Lincoln et al. (2013) found that women with scores above 9 on the Women's Health Initiative (WHI) Insomnia Rating Scale had a 27\% increased risk for cardiovascular diseases. In their meta-analysis, Sofi et al. (2012) noted that there is a $45 \%$ increased risk of developing or dying from cardiovascular diseases if insomnia is present.

Chronic insomnia is also found in individuals with physician-diagnosed cardiovascular diseases. Taylor et al.'s (2007) findings suggest that $44.1 \%$ of individuals with a heart disease reported experiencing insomnia compared to only $22.8 \%$ of those without a heart disease. Johansson et al. (2010) found that of participants with heart failure, $72 \%$ experienced the insomnia symptom of difficulty maintaining sleep and $25 \%$ experienced excessive daytime sleepiness. Participants without a diagnosis of a heart disease only experienced these same symptoms $50 \%$ and $8 \%$, respectively. 
One proposed mechanism that links chronic insomnia with cardiovascular disease is the state of hyperarousal that occurs during the day and throughout the night in individuals with chronic insomnia (Javaheri \& Redline, 2017; Taylor et al., 2017). Hyperarousal can lead to increased sympathetic nervous system activity, along with the release of inflammatory cytokines which are found in cardiovascular diseases (Ham et al., 2017; Javaheri \& Redline, 2017; Taylor et al., 2017). In reviewing the evidence on chronic insomnia and cardiovascular disease, it is evident that there is a link between the two conditions; however, there is limited evidence on whether individuals with current physician-diagnosed cardiovascular disease experience chronic insomnia symptoms differently than individuals without a cardiovascular disease diagnosis. Therefore, the first focus of this study is to examine the difference in experience of chronic insomnia symptoms between individuals with cardiovascular diseases and individuals without cardiovascular diseases.

\section{Research Problem}

The experience of chronic insomnia in the cardiovascular population is of importance in the Canadian context as Statistics Canada has reported that cardiovascular diseases (CVD) remains the second leading cause of death in the Canadian population (Statistics Canada, 2017). Currently, approximately 1.6 million Canadians are living with some form of cardiovascular disease (Public Health Agency of Canada, 2009, p. 2). In 2000, approximately 22.2 billion dollars was spent on the management and care of CVD (PHAC, 2009, p. 5). At an individual level, much like chronic insomnia, CVD has been associated with emotional distress and increased cardiac symptom intensity, leading to greater use of health care (Ketterer et al., 2008) and decreased quality of life (Redeker et al., 2010; Thase, 2005). 
In their prospective study, Fernandez-Mendoza, Vgontzas, \& Liao (2012) noted that chronic insomnia is associated with twofold increased risk of hypertension development. This may be due to the excessive sympathetic nervous system response which leads to overall increases in vascular resistance (Kasper \& Knudson, 2010). Additionally, Laugsand et al. (2011) found that difficulty initiating sleep was the insomnia symptom most strongly associated with incident myocardial infarction; this association reflects a $45 \%$ increased risk for future myocardial infarction.

Although positive associations between insomnia and cardiovascular diseases are reported in the previously mentioned studies, the available evidence has some limitations. Many of these studies used a one-time self-report questionnaire to assess insomnia (FernandezMendoza et al., 2012; Hoevenaar-Blom et al., 2011; King et al., 2008; Laugsand et al., 2011; Strand et al., 2016). Such questionnaires rely on the accuracy of an individual's recall of their overall sleep experience at a single point in time. Use of a sleep diary provides a more accurate assessment of overall sleep and indicators of insomnia as individuals are provided the opportunity to report and reflect on their sleep disturbances prospectively, over a longer period (Ciano et al., 2017). Another limitation is that although sleep apnea has been found to have a detrimental effect on atherosclerosis progression and development of cardiovascular disease, it was not assessed and controlled for in previous studies (Drager et al., 2005; Marin, Carrizo, Vincente, \& Augusti, 2005). In failing to control for sleep apnea, results from these studies may be explained by this confounding variable. Finally, only two studies examined the experience of chronic insomnia in individuals with physician-diagnosed cardiovascular diseases (Johansson et al., 2010; Taylor et al., 2007); all other studies focused on whether the experience of insomnia acted as a precursor to the development of cardiovascular diseases. However, understanding the 
concurrent experiences of chronic insomnia symptoms and cardiac symptoms, rather than solely focusing on the risk of cardiovascular disease development from chronic insomnia, would be informative in guiding the selection of interventions to safely manage chronic insomnia in this population.

Cardiac symptoms are indicators of cardiovascular disease and reflect the pathophysiological nature of disease progression. Johnson et al. (2006) found that in women, the experience of persistent chest pain was associated with a three-fold increased risk of the future experience of non-fatal myocardial infarction, as well as a $30 \%$ increased rate of cardiovascular disease-related death when compared with women without persistent chest pain. Fredericks, Sidani, Miranda, \& Fox (2016) found that in community-dwelling individuals with chronic insomnia, increased perceived severity of insomnia symptoms was positively associated with the frequency and severity of cardiac symptoms including chest pain, heart racing, difficulty breathing, fainting, and dizziness. Asplund and Aberg (2003) found that poor sleep resulted in spasmodic chest pain and irregular heart beats. In a qualitative study exploring cardiac symptoms and sleep among a cardiovascular population, Broström, Strömberg, Dahlström, \& Fridlund (2001) found that individuals with congestive heart failure reported experiencing shortness of breath and dysrhythmias that led to more frequent awakenings at night as well as negative sleep experiences.

Overall, evidence suggests that the experience of cardiac symptoms in individuals who have not been diagnosed with a cardiovascular disease is related to the experience of chronic insomnia, however, there is limited evidence of this relationship in individuals with cardiovascular diseases. As cardiac symptoms represent the presence of cardiovascular diseases and have been associated with the presence of sleep disturbance, the second focus of this study 
will be to determine if there is an association between experience of chronic insomnia symptoms and cardiac symptoms amongst persons with cardiovascular diseases (CVD).

\section{Study Purpose}

The purpose of this study is twofold: 1) to determine if a difference exists in the presence of chronic insomnia symptoms (difficulty initiating sleep, difficulty maintaining sleep, sleep efficiency, insomnia severity, and daytime sleepiness) between individuals with CVD and individuals without CVD, and 2) to examine the relationship between chronic insomnia symptoms and cardiac symptoms including chest pain, troubled breathing, dizziness, fainting, and heart racing in individuals with cardiovascular diseases and individuals without cardiovascular diseases.

\section{Clinical Significance}

Currently, the primary treatment for chronic insomnia is the administration of hypnotics and sedatives (Buysse et al., 2017, Taylor et al., 2017), the use of which can arguably lead to polypharmacy, the experience of adverse effects of these medications, as well as the effects of the drug interactions with commonly prescribed cardiovascular medications. Another treatment modality is that of cognitive behavioural therapy, which includes education on effective sleep habits, stimulus control, relaxation, and time-in-bed restriction (Buysse et al., 2017; Maness \& Khan, 2015). This therapy has been shown to be effective for approximately $70 \%$ to $80 \%$ of participants suffering from chronic insomnia (Buysse et al., 2017). However, Taylor et al. (2007) stated that more work is needed in the treatment of comorbid chronic insomnia in persons with cardiovascular diseases. Although evidence suggests that chronic insomnia is a precursor to cardiovascular diseases, little is known about the experiences of chronic insomnia in persons 
who are already diagnosed with cardiovascular diseases. In completing this study, knowledge will be developed in understanding the experience of insomnia and cardiac symptoms in individuals with cardiovascular diseases, who are also suffering from chronic insomnia. As Taylor et al. (2007) suggest, even a small reduction in the experience of chronic insomnia can decrease the symptoms associated with other chronic illnesses, such as cardiac symptoms in cardiovascular diseases. Therefore, understanding the association between chronic insomnia and cardiac symptoms in persons with cardiovascular diseases will guide healthcare providers in designing effective interventions targeted at individuals diagnosed with cardiovascular diseases. 


\section{Chapter Two: Literature Review and Conceptual Framework}

This chapter summarizes and critically appraises the literature supporting the need to investigate the relationships between chronic insomnia and cardiac symptoms in persons with cardiovascular diseases (CVD). Following the review of the literature, the conceptual framework derived from the findings of the literature is described. Included in this conceptual framework are the conceptual definitions for chronic insomnia and cardiac symptoms, followed by a description of the relationships and synthesis of relevant evidence. Finally, the hypotheses derived from the conceptual framework propositions are presented.

\section{Literature Search}

The databases used to acquire the selected articles included Medline, CINAHL, HealthStar, and PubMed. Date range was limited to the years 2000-present. The key words used in the search were insomnia, sleep, sleep wake OR sleep-wake transition disorders, sleep initiation and maintenance disorders, difficulty initiating sleep, difficulty maintaining sleep, early morning awakenings, sleep onset latency, wake after sleep onset, sleep efficiency, cardiac symptoms, angina pectoris, arrhythmias - cardiac OR irregular heartbeat, chest pain, dyspnea, dizziness, syncope, troubled breathing, and cardiovascular disease(s). Where indicated above, the Boolean operator 'OR' was used to broaden the results of specific search terms. Terms used independently resulted in thousands of results, therefore the Boolean operator 'AND' was used to combine the various search terms in multiple combinations. The combination of terms resulted in a total of 1,023 articles, which were reviewed by title and abstract.

Inclusion criteria were articles published in English language and focusing on insomnia/sleep disorders in the CVD population and having examined cardiac and insomnia 
symptoms. In total, 49 articles met the inclusion criteria. After examination of each article in its entirety, 33 were excluded due to their focus on an alternative population and variables. A total of 16 articles were included in the review; 12 examined the relationship between insomnia and CVD (Canivet, Nilsson, Lindeberg, Karasek, \& Östergren, 2014; Javaheri \& Redline, 2017; Johansson et al., 2010; Laugsand et al., 2011; Laugsand et al., 2014; Li, Zhang, Hou, Tang., 2014; Y. Li et al., 2014; Mallon, Broman \& Hetta, 2002; Philips \& Mannino, 2007; SandsLincoln et al., 2012; Sofi et al., 2012; Taylor et al., 2007), 3 examined the relationship between insomnia and cardiac symptoms (Asplund, 2003; Belleville et al., 2014; Broström et al., 2001), and 1 examined the relationship between insomnia, CVD, and cardiac symptoms (EdéllGustaffson, 2002).

\section{Findings}

\section{Insomnia and Cardiovascular Diseases (CVD)}

Relationship of insomnia with CVD. Evidence from meta-analyses and systematic reviews (M. Li et al., 2014; Sofi et al., 2012) suggest presence of insomnia is associated with a $33 \%-45 \%$ increased risk of development and death from cardiovascular diseases and their associated events, including myocardial infarction (RR 1.41, 95\% CI, 1.18-1.67, $\mathrm{p}=0.000 ; \mathrm{RR}$ $1.45,95 \% \mathrm{CI}, 1.29-1.62, \mathrm{p}<0.0001)$. These results are replicated in Javaheri \& Redline (2017) in that insomnia is associated with an increased risk of developing cardiovascular diseases including hypertension, coronary heart disease, acute coronary syndrome, and heart failure.

Insomnia symptoms have also been assessed using a variety of measures. One retrospective study used a sleep diary to assess insomnia (Taylor et al., 2007); findings suggest individuals diagnosed with chronic insomnia experienced increased incidence of heart disease 
and high blood pressure ( $21.9 \%$ vs. $9.5 \% ; 43.1 \%$ vs. $18.7 \%$ respectively) when compared with individuals free from chronic insomnia.

Six studies (Canivet et al. 2017; Laugsand et al. 2011; Laugsand et al., 2014; Y. Li et al., 2014; Mallon et al., 2002; Phillips \& Mannino, 2007;) examined the relationship between insomnia and CVD using Likert-scale questions to assess the presence of insomnia symptoms. Evidence suggests the experience of insomnia symptoms (difficulty initiating sleep, difficulty maintaining sleep, and non-restorative sleep) are associated with an increased incidence of CVD both independently (HR 1.45, 95\% CI, 1.18-1.80; HR 1.20, 1.01-1.68; HR 1.27, 1.03-1.57, respectively, and HR 1.4, 95\% CI, 1.2-1.6), and when combined (OR 1.5, 1.1-2.0) (Canivet et al. 2017; Laugsand et al. 2011; Phillips \& Mannino, 2007). Specifically, the effects of insomnia symptoms are dose dependent; that is, the risk of heart failure increases with the number of symptoms experienced with an HR for one symptom (HR 0.96, 0.57-1.61), two symptoms (HR $1.35,0.72-2.50$ ), and three symptoms (HR 4.53, 1.99-10.30) (Laugsand et al., 2014). Evidence also suggests that experience of difficulty initiating sleep (a symptom of insomnia) is associated with both an increased incidence of coronary artery disease death in men (RR 3.1, 95\% CI, 1.5$6.3, \mathrm{p}<0.01$ ), and increased risk for cardiovascular mortality regardless of confounders such as age, ethnicity, body mass index, and smoking history (Y. Li et al., 2014; Mallon et al., 2002).

Finally, one study used a validated screening tool to determine the effect of insomnia on the development of CVD. Sands-Lincoln et al. (2013) noted women who scored high on the Women's Health Initiative (WHI) Insomnia Rating Scale had a higher risk for the development of CVD (HR 1.11, 95\% CI, 1.03-2.00) even after controlling for age and race.

Concurrent CVD and insomnia. Taylor et al. (2007) reported higher rates of chronic insomnia in participants with a diagnosed heart disease in comparison to those free from heart 
disease (44.1\% vs. $22.8 \%$ ). Two studies examined the experience of insomnia in those with CVD using a validated screening tool (Edéll-Gustaffson, 2002; Johansson et al., 2010). Using the Uppsala Sleep Inventory Scale, both studies found that individuals diagnosed with CAD or HF experienced difficulties maintaining sleep. Additionally, 25\% of participants also experienced excessive daytime sleepiness as measured with the Epworth Sleepiness Scale (Johansson et al., 2010).

Limitations of Literature. A significant limitation of these studies is the wide range of tools used for measuring insomnia. Multiple studies used Likert-Scale measurements that are not content-validated and do not demonstrate adequate reliability and validity (Canivet et al., 2014; Y. Li et al., 2014; Laugsand et al., 2011; Laugsand et al., 2014; Mallon et al., 2002; Phillips \& Mannino, 2007). Another major limitation is the lack of control for obstructive sleep apnea (Canviet et al., 2014; Laugsand et al., 2011; Laugsand et al., 2014; Y. Li et al., 2014; SandsLincoln et al., 2013). Presence of obstructive sleep apnea has been shown to have a positive effect on atherosclerosis progression and thereby is a contributor to the development of cardiovascular disease (Drager et al., 2005; Marin et al., 2005); failing to control for sleep apnea may introduce confounding and weaken the validity of study results.

\section{Insomnia and Cardiac Symptoms}

Evidence on the relationship between insomnia and cardiac symptoms is limited.

Evidence suggests that in individuals with diagnosed CVD, experience of cardiac symptoms such as dyspnea and palpitations negatively affect sleep by inducing anxiety and consequent disrupted sleep (Broström et al., 2001), while sleep initiation problems increase the experience of cardiac symptoms such as heart racing $(r=0.36, \mathrm{P}<0.05)$ (Edéll-Gustaffson, 2002). In a survey of 6103 older adults, Asplund (2003) found that $15.7 \%$ of men and $33.4 \%$ of women $(p<0.001)$ 
reported poor sleep; of these, $11.8 \%$ of men and $13.1 \%$ of women also experienced irregular heartbeats, and $12.9 \%$ of men and $10.6 \%$ of women experienced spasmodic chest pain. These findings demonstrate a correlation between subjective experiences of poor sleep and presence of cardiac symptoms. Finally, in a secondary analysis of a cross-sectional study, Belleville et al. (2014) found that insomnia symptom severity assessed with the Insomnia Severity Index accounted for $1.3 \%$ of the variance in chest pain severity among participants.

Limitations of Literature. In the few studies examined, there have been no consistent measures of cardiac symptoms and insomnia symptoms. In Asplund (2003), poor sleep rather than insomnia was the focus of the study, and cardiac symptoms were measured using dichotomous single items to assess for presence of spasmodic chest pain and irregular heartbeats; neither symptom frequency nor distress was measured. Overall, there is limited literature on the relationship between cardiac symptoms and insomnia in persons with and without cardiovascular disease.

\section{Summary of Findings}

Evidence demonstrates that experience of insomnia increases the risk of CVD (Canivet et al., 2014; Javaheri \& Redline, 2017; Laugsand et al., 2011; Lausand et al., 2014; M. Li et al., 2014; Y. Li et al., 2014; Mallon et al., 2002; Phillips \& Mannino, 2007; Sands-Lincoln et al., 2013; Sofi et al., 2012; Taylor et al., 2007). However, only three studies (Edéll-Gustaffson, 2002; Johansson et al., 2010; Taylor et al., 2007) examined the experience of chronic insomnia in individuals with concurrent cardiovascular diseases. This indicates that there is limited evidence examining whether individuals with CVD have a greater experience of chronic insomnia symptoms than the general population. Therefore, this study will address this gap by determining 
whether there is a difference in the experience of chronic insomnia symptoms between individuals with CVD and individuals without CVD.

Additionally, the most common indicator of damage to the cardiac system is the experience of cardiac symptoms including chest pain, dyspnea, dizziness, syncope, and arrythmia (Hannon, Pooler, \& Porth, 2010; Lewis, Barry, Goldsworthy, \& Goodridge, 2010; Mansen \& Gabiola, 2015). Limited evidence supports an association between the experience of chronic insomnia and cardiac symptoms (Asplund, 2003; Belleville et al., 2014). This study will address this gap by examining the relationship between chronic insomnia and cardiac symptoms in both the CVD and non-CVD populations.

\section{Conceptual Framework}

The conceptual framework guiding this study was derived from the findings of the literature. Conceptual definitions for chronic insomnia and cardiac symptoms are presented. Relationships found from the empirical evidence are then outlined and guide the statement of the study hypotheses.

\section{Conceptual and Operational Definitions}

\section{Indicators of Chronic Insomnia}

Chronic insomnia is a common sleep disorder characterized by difficulty initiating sleep, difficulty maintaining sleep and/or early morning awakening, associated with impaired daytime functioning, occurring at least three times a week for at least six consecutive weeks (Buysse et al., 2017; Ciano et al., 2017; Maness \& Khan, 2015; Medalie \& Cifu, 2017). Assessment of symptoms of chronic insomnia include self-report on sleep difficulties, sleep onset latency, 
waking up after sleep onset, sleep efficiency, and impaired daytime functioning (Ciano et al., 2017), as well as overall insomnia severity.

Difficulty initiating sleep. Difficulty initiating sleep is a symptom of insomnia and is described as the subjective experience of having trouble falling asleep (Bertisch et al., 2018; Chakravorty et al., 2015). It is indicated by sleep onset latency (SOL) which is the amount of time between the initial attempt to initiate sleep and the actual time sleep occurs. A sleep onset latency of $\geq 30$ minutes is an indicator of difficulty initiating sleep (Morin et al., 2009).

Difficulty maintaining sleep. Difficulty maintaining sleep is described as the subjective experience of trouble staying asleep or returning to sleep after waking up following sleep onset (Bertisch et al., 2018; Chakravorty et al., 2015). Difficulty maintaining sleep is indicated by wake after sleep onset (WASO). WASO quantifies the amount of time spent awake after initiating sleep, across all awakenings (Lee et al., 2016). WASO of $\geq 30$ minutes is an indicator of difficulty maintaining sleep (Fredericks et al., 2016).

Sleep efficiency. Sleep efficiency is a parameter of sleep and is determined by calculating the value of total time asleep out of the total time spent in bed (Miranda, Sidani, Fredericks, \& Fox, 2017). A value of $>80 \%$ indicates good efficient sleep (Buysee et al., 2011; Miranda et al., 2017).

Insomnia severity. Insomnia severity is an indicator of perceived satisfaction and distress with overall sleep patterns (Bastien, Vallières, \& Morin, 2001; LeBlanc et al., 2007). Insomnia severity is measured using the Insomnia Severity Index (Morin, 1993), where a total score over 15 indicates moderate to high severity (LeBlanc et al., 2007; Morin, 1993). 
Impaired daytime functioning. Impaired daytime functioning reflects the subjective experience of daytime sleepiness (Johns, 1991). Impaired daytime functioning is measured using the Epworth Sleepiness Scale (Johns, 1991), where a total score above 16 indicates high levels of daytime sleepiness.

\section{Predictors of Chronic Insomnia}

Predictors of insomnia include female sex (Chaput et al., 2017; Ciano et al., 2017, Sorscher, 2017, Sutton, Moldofsky, \& Badley, 2001), old age (Ciano et al., 2017, Rediehs, Reis, Creason, 1990; Campbell, Gillin, Kripke, Erikson, \& Clopton, 1989), and low educational attainment (Gellis et al., 2005; Jackson, Redline, \& Emmons, 2015). Chaput et al. (2017), in their cross-sectional Canadian Health Measures survey found that when considering individual insomnia symptoms, women experienced more difficulty with falling asleep (55\% vs. $45 \%)$ and staying asleep (35\% vs. $25 \%)$ than their male counterparts. Tessaro \& Navarro-Peternella (2015) indicated $63 \%$ of women had difficulty falling asleep, while $36 \%$ reported difficulty maintaining sleep. These results are consistent with evidence showing that the incidence rates of insomnia are between 25\%-42\% in the female population (Ciano et al., 2017; Ham et al., 2017).

Additionally, Ciano et al. (2017) reported 31\%-42\% of peri-menopausal women experience insomnia; this rate increases by 1.3 for women in late menopause (95\%CI, [1.2, 1.5], $\mathrm{p}<0.001)$. The increased incidence of insomnia in both older adults and older women may be due to a dysregulation in the circadian rhythm that controls sleep (Gulia \& Kumar, 2018). As individuals age, it is proposed that this 'internal clock' system is altered particularly in the hypothalamus with a decline in the functioning of the suprachiasmatic nucleus. This change results in a sleep cycle that is initiated earlier in the day (Gulia \& Kumar, 2018). Additionally, the circadian rhythm is thought to control other physiological functions such as melatonin 
production and body temperature (Gulia \& Kumar, 2018). Melatonin is a hormone that is secreted when the body perceives decreased environmental light. It regulates the sleep-wake cycle by inducing sleep through a reduction in arousal and brain activity, decrease in body temperature, and delay of the production of cortisol, which increases blood pressure and blood sugar, negatively affecting sleep (Wade \& Downie, 2008). The level of melatonin increases at night, influencing the body to revert to sleep. However, the amount of melatonin appears to decrease with age (Gulia \& Kumar, 2018). In addition to these generalized circadian rhythm changes found in older adults it has been noted that women are more strongly affected by the temperature changes associated with circadian rhythm deterioration (Campbell et al., 1989). The literature suggests that Electroencephalograhy (EEG)-demonstrated wakefulness after sleep onset is strongly associated with minimum nocturnal temperature; of both sexes, older women appear to experience an earlier temperature acrophase than men $(\mathrm{p}<0.03)$, indicating a lower body temperature at night (Campbell et al., 1989).

Regarding education, in their prospective study Gellis et al., (2005) reported individuals who dropped out of high school were 3.9 times more likely to experience insomnia when compared to college graduates, even after controlling for ethnicity, sex, and age. It was also found that each additional year of educational attainment decreased the incidence of insomnia by 13\% (Jackson et al., 2015). Gellis et al. (2005) and Jackson et al. (2015) propose that having a higher educational attainment protects against chronic insomnia by providing individuals with healthy behaviours, assets, and problem-solving skills, thereby decreasing the likelihood that these individuals will suffer from negative life experiences that cause distress and insomnia. Additionally, Jackson et al. (2015) propose that individuals with lower educational attainment 
are more likely to experience job, psychosocial, and environmental stresses that may ultimately affect their sleep.

\section{Consequences of Chronic Insomnia}

Consequences of chronic insomnia, as outlined in the previous chapter, include cognitive impairments, anxiety and depression, poor work performance, absenteeism, decreased quality of life, increased likelihood of developing chronic illnesses including cardiovascular diseases, and increased incidence of mortality (Maness \& Khan, 2015; Sorscher, 2017; Taylor et al., 2007; Thase, 2005).

\section{Indicators of Cardiac Symptoms}

In general, cardiac symptoms are nonspecific symptoms that can demonstrate exacerbations of physiological disturbances in body systems including the respiratory, musculoskeletal, neurological, and gastrointestinal systems, and are also the primary indicators of cardiac dysfunction (Hannon et al., 2010; Lewis et al., 2010; Mansen \& Gabiola, 2015). Although supported by limited evidence, there is also a linkage between experience of disordered sleep and cardiac symptoms including chest pain, dyspnea, and arrythmias perceived as palpitations (Asplund, 2003; Belleville et al., 2014; Broström et al., 2001; Edéll-Gustaffson, 2002).

Chest pain. Chest pain is experienced as constrictive, heavy, suffocating, or choking, and can radiate from the chest to the back, jaw, shoulders, or arms (DeVon, Pettey, Vuckovic, Koenig, \& McSweeny, 2016; Grubb, 2002; Kreatsoulas, Shannon, \& Giacomini, 2013; Lewis et al., 2010). Chest pain, when associated with cardiac etiology, is primarily due to myocardial ischemia which is a decreased myocardial oxygen supply (Lewis et al., 2010). Additionally, 
anxiety which is associated with insomnia, has been reported with chest pain experience (Ketterer et al., 2008).

Dyspnea. Dyspnea is the subjective experience of troubled breathing, laboured breathing, and discomfort from breathing (Ketterer et al., 2008; Mansen \& Gabiola, 2015). In persons with cardiovascular diseases, dyspnea tends to increase upon lying flat and can be relieved by sitting in an upward position; it is generally related to systolic and diastolic dysfunction, cardiac ischemia, pulmonary edema from left ventricular failure, as well as reduced cardiac output (Grubb, 2002; Mansen \& Gabiola, 2015). Additionally, anxiety has also been associated with the experience of dyspnea and insomnia (Ketterer et al., 2008).

Dizziness. Dizziness is subjectively experienced as feeling faint and/or unsteady (Grubb, 2002; Ketterer et al., 2008; Mansen \& Gabiola, 2015), and tends to occur after a change in position. In persons with cardiovascular diseases, dizziness occurs with a lack of blood flow to the reticular activating system in the brain stem due to experience of arrythmias (Lewis et al., 2010).

Syncope. Syncope is defined as a lapse in consciousness and can be accompanied by a loss in postural tone, otherwise known as fainting (Lewis et al., 2010). It is predicted by the subjective feeling of faintness or dizziness and can be associated with blurred vision and palpitations (Hannon et al., 2010; Ketterer et al., 2008). Relative to cardiac etiology, syncope can be caused by dysrhythmias (e.g. arrythmia, tachycardia, and bradycardia) and decreased cardiac output (Grubb, 2002; Lewis et al., 2010).

Arrythmia. Arrythmias can be experienced as different sensations including palpitations associated with an altered cardiac rhythm (Grubb, 2002). These changes in cardiac rhythm 
include tachycardia and bradycardia, as well as other irregular rhythms such as atrial fibrillation and atrial flutter (Grubb, 2002; Lewis et al., 2010). Additionally, arrythmias can occur due to the body's sympathetic nervous system activation, which compensates for decreased cardiac output found in heart failure by increasing heart rate (Lewis et al., 2010). Palpitations can be indicated by dizziness and presyncope, flushing, and weakness (Grubb, 2002; Kreatsoulas et al., 2013) as well as heart pounding and/or racing (Ketterer et al., 2008). However, palpitations can also lead to dizziness, syncope, and dyspnea (Lewis et al., 2010).

\section{Predictors of Cardiac Symptoms}

Cardiac symptoms are strongly predicted by cardiac dysfunction, which is aggravated by smoking, hypertension, high low-density lipoproteins, obesity, diabetes, physical inactivity and stress (Lewis et al., 2010; Ryan, DeVon, \& Zerwic, 2005). Progression of CVD to adverse cardiac events such as MI, aortic dissection, and pulmonary embolism are also predictors of cardiac symptoms (Grubb, 2002). Additional predictors include physical exertion, consumption of tobacco and other stimulants, and extremes in temperature (Gallagher, Marshall, \& Fisher, 2010; Grubb, 2002; Hannon et al., 2010; Lewis et al., 2010). Non-cardiac predictors of cardiac symptoms include stress, depression, anxiety, and low sleep quality (Wikman et al., 2012). Cardiac symptoms including chest pain and irregular heart beats can also be predicted by poor sleep, and insomnia symptom severity (Asplund, 2003; Belleville et al., 2014; Edéll-Gustaffson, 2002).

\section{Consequences of Cardiac Symptoms}

Cardiac symptoms including chest pain, dyspnea, dizziness, syncope, and arrythmia can act as prodromal symptoms for cardiac dysfunction. These symptoms can indicate the presence 
of an acute coronary syndrome reflected by sustained myocardial ischemia (Lewis et al., 2010). This can then progress to further cardiac damage through heart failure, dysrhythmias, and cardiogenic shock (Lewis et al., 2010; Ryan et al., 2005). With the progression of cardiac symptoms increases in morbidity and mortality are seen, as well as increases in the development of depression (DeVon et al., 2016; Ryan et al., 2005; Wikman et al., 2012). Experience of cardiac symptoms also have a negative effect on sleep efficiency, and quality of life (Broström et al., 2001; Husser, Bollmann, Kühne, Molling, \& Klein, 2012; Ten Voorde, van der ZaagLoonen, \& van-Leeuwen, 2012).

\section{Relationships Under Study}

\section{Insomnia and CVD}

Overall, presence of chronic insomnia is associated with increased incidence of heart disease; presence of heart disease is associated with increased incidence of chronic insomnia (Taylor et al., 2007). Presence of insomnia is associated with increased risk for development of cardiovascular diseases (Javaheri \& Redline, 2017; M. Li et al., 2014; Sofi et al., 2012; Taylor et al., 2007). Similarly, presence of specific insomnia symptoms (i.e. difficulty initiating sleep, difficulty maintaining sleep, and non-restorative sleep) is associated with increased incidence of cardiovascular diseases (Canivet et al., 2014; Laugsand et al., 2011; Laugsand et al., 2014; Y. Li et al., 2014; Mallon et al., 2002; Phillips \& Mannino, 2007).

Presence of heart disease (e.g. heart failure, and coronary artery disease) is associated with increased incidence of chronic insomnia manifested in difficulty initiating and maintaining sleep, and excessive daytime sleepiness (Edéll-Gustaffson, 2002; Johansson et al., 2010; Taylor et al., 2007). 


\section{Insomnia and Cardiac Symptoms}

Individuals with cardiovascular disease experience dyspnea and dysrhythmia which have been associated with difficulty maintaining sleep (Broström et al., 2001). In individuals with cardiovascular disease, difficulty initiating sleep has been associated with heart racing (EdéllGustaffson, 2002). Experience of poor sleep has been associated with incidence of arrythmias and chest pain (Asplund, 2003). Finally, insomnia severity has been demonstrated to explain a $1.3 \%$ variance in experience of chest pain (Belleville et al., 2014).

\section{Hypotheses}

The hypotheses examined in this study were derived from the conceptual framework. They are:

1) There is a significant difference in experience of chronic insomnia symptoms between individuals diagnosed with CVD and individuals who do not have a diagnosis of CVD.

2) There is a positive relationship between experience of chronic insomnia symptoms and experience of cardiac symptoms in individuals diagnosed with CVD and individuals who do not have a diagnosis of CVD. 


\section{Chapter 3: Methodology}

This project is a secondary analysis of an original study (Miranda et al., 2017). A brief summary of the original study is provided; this is followed by a description of research methods. Specifically, the design, sample, power analysis, variables and measures, and data analysis are presented.

\section{Overview of Original Study}

The original study involved a randomized controlled trial to examine the effects of stimulus control therapy (SCT) and sleep restriction therapy (SRT) on cardiac symptoms and insomnia in persons with chronic insomnia, who did and did not have cardiac diseases (Miranda et al., 2017). Participants were randomly assigned to one of three groups (stimulus control therapy, sleep restriction therapy, and no-treatment control), and outcome data were collected at baseline, and after the four-week period of treatment. SCT is a behavioural therapy that aims to reacquaint the bedroom and bed with sleeping; it consists of multiple instructions for developing consistent sleep habits and sleep patterns (Miranda et al., 2017). These instructions include: use the bed for sleep only, avoid naps, remove oneself from bed if unable to sleep, and return to bed only when sleepy. SRT is a behavioural therapy aimed at consolidating sleep to a specific time frame through restricting time spent in bed; the time in bed is determined by examining an individual's sleep diary to identify how much sleep they require, after which a new sleep-wake schedule is agreed upon (Miranda et al., 2017). Both SCT and SRT were provided by Master's prepared nurses, who received extensive training in the underlying theory and the implementation of the therapies' protocol. Variables examined in the original study that were also used in this secondary analysis include variables reflecting participants' demographic characteristics: gender, cardiac disease presence, age, and years of formal education; variables 
pertaining to chronic insomnia: difficulty initiating sleep (sleep onset latency), difficulty maintaining sleep (wake after sleep onset), sleep efficiency, insomnia severity, and impaired daytime functioning; and variables pertaining to cardiac symptoms: chest pain, dyspnea, dizziness, syncope, and arrhythmia.

Inclusion criteria for the study included community-dwelling adults 40 years and older, living in Toronto. Additionally, all participants were required to read and write English (to ensure adequate understanding of study information needed for informed consent and treatment instructions) and to have chronic insomnia; chronic insomnia was manifested as the presence of difficulty initiating sleep, difficulty maintaining sleep, and early morning awakenings, demonstrated through sleep onset latency and wake after sleep onset equal to, or greater than 30 minutes per night respectively, on at least 3 nights a week, for at least 6 weeks in duration, as indicated by responses to respective items of the Insomnia Interview Schedule (Fredericks et al., 2016; Miranda et al., 2017; Morin, 1993). Exclusion criteria included a diagnosis or current treatment for sleep apnea (as assessed with the respective items on the Insomnia Interview Schedule) and/or cognitive impairment identified by a score below 24 on the Mini-Mental State Exam (Folstein, Folstein, \& McHugh, 1975; Fredericks et al., 2016; Miranda et al., 2017).

Multiple strategies were used to recruit participants and consisted of placing advertisements in free newspapers available in the public transportation system. Flyers were distributed to hospital ambulatory services, community health centres, and sleep clinics in Toronto. Finally, advertisements were placed on commercial websites such as 'Kijiji' as well as in newsletters and magazines targeting middle-aged and older adults (Miranda et al., 2017). Data collection occurred at the research center of an academic institution in the city of Toronto, 
Ontario, Canada. Data were collected in an accessible meeting room where privacy and confidentiality were maintained.

A research assistant interviewed interested participants through telephone for initial eligibility after securing verbal agreement. Individuals were assessed for their English language comprehension, age, presence of sleep apnea, type and duration of insomnia, and daytime impairment. The research assistant provided eligible participants with an explanation of the study and mailed them a daily sleep diary with written instructions to complete for one week. Additional screening for cognitive impairment was done in a face-to-face interview, during which the research assistant administered the Mini-Mental State Exam, after obtaining participants' written consent. Approval for the study was obtained from the Research Ethics Board at the academic institution.

\section{Design for Secondary Analysis}

This study incorporated a quantitative and descriptive approach to examine 1) the difference in the experience of chronic insomnia symptoms between persons with chronic insomnia who are diagnosed with CVD and individuals with chronic insomnia who are not diagnosed with CVD and 2) the relationship between chronic insomnia symptoms and cardiac symptoms, within groups (CVD and non-CVD). In this study, data collected at a single point (baseline in the original study) were obtained from two naturally occurring groups (those with CVD and those without CVD).

\section{Sample}

Inclusion criteria for this secondary analysis were determined by the original study criteria. The sample size for this study was limited by the number of participants who reported 
having CVD at baseline. A comparable number of participants without CVD was selected through systematic random sampling. Using this method, two naturally occurring groups (those with CVD and those without CVD) were formed.

\section{Power Analysis}

Power analysis for statistical testing was based on the following criteria: sample size, plevel, power, and effect size.

\section{Sample Size}

Of persons with chronic insomnia enrolled in the original study, all participants reporting having CVD were included $(n=33)$. A random sample of 36 participants who did not have CVD was selected. This resulted in 69 participants in total. With this sample size, using Cohen's criteria (1988), this study was powered to detect medium $(\mathrm{d}=.4 ; \mathrm{r}=.3)$ to large $(\mathrm{d}=.8 ; \mathrm{r}=.5)$ between group differences (Hypothesis 1) and correlation between variables within each group (Hypothesis 2).

\section{p-Level}

The p-level is set at .05 as this is the generally accepted level for determining statistical significance in descriptive and comparative studies (Edéll-Gustafsson, Svanborg, \& Swahm, 2006; Gray, Grove, \& Sutherland, 2017; Ham et al., 2017; King et al., 2008).

\section{Power}

The conventional power of .80 was used to identify potential differences between groups and/or relationships between variables (Cohen, 1988). 


\section{Effect Size}

It is anticipated that a sample of 69 participants will allow for the identification of a medium to large effect size for the between group comparisons and associations between the variables of interest within each group (Hertzog, 2008). Effect size was calculated using the webbased Social Sciences Statistics (2019) effect size calculator tool, which calculates the mean difference of the two groups and divides this by the pooled standard deviation.

\section{Variables and Measures}

\section{Demographic Variables}

The demographic variables assessed in this secondary analysis included gender, cardiac disease presence, age, and years of formal education. Gender was measured using one item with a dichotomous response option (male or female). Presence of cardiac disease was measured with one item reporting on whether or not (yes or no) participants have been diagnosed with a cardiac disease. Age was measured as a continuous variable, with participants asked to provide their age in exact years. Years of formal education was measured as the number of years of formal education.

\section{Symptoms of Chronic Insomnia}

Difficulty initiating sleep (DIS). Difficulty initiating sleep was indicated by sleep onset latency (SOL). A SOL of $\geq 30$ minutes for 6 or more weeks is an indicator of chronic insomnia (Fredericks et al., 2016; Morin et al., 2009). In this study, SOL was measured with one item on the Daily Sleep Diary inquiring about the length of time (in minutes) it took the participant to fall asleep. 
The Consensus Daily Sleep Diary is a self-administered nightly log that assesses for sleep parameters including the time participants went to bed, time they woke up, and number and length of each nocturnal awakening (Carney et al., 2012). In this study, participants were asked to complete the diary daily for one week; each morning participants sent their responses by voicemail or email to the research team. The Daily Sleep Diary has shown adequate test-retest reliability and validity, evidenced by moderate correlations of the sleep parameters estimated by the diary and those estimated with actigraphy (Buysee, Rush, \& Reynolds, 2017).

Difficulty maintaining sleep (DMS). Difficulty maintaining sleep was indicated by wake after sleep onset (WASO). In this study, WASO was measured by the Daily Sleep Diary as a continuous variable at the interval level, representing the total number of minutes the person stayed awake across all awakenings (Buysse et al., 2011).

Sleep efficiency (SE). SE is an indicator of chronic insomnia. In this study, SE was measured as a continuous variable and was calculated as the percentage of time spent actually asleep out of the total time spent in bed. A value $>80 \%$ indicates high levels of sleep efficiency (Buysee et al., 2011).

Insomnia severity. Insomnia severity was measured by the Insomnia Severity Index developed by Morin (1993). The Insomnia Severity Index (ISI) is a 7-item Likert scale questionnaire assessing perceived severity of insomnia, satisfaction with sleep patterns and distress with sleep problems (Bastien et al., 2001; LeBlanc et al., 2007). The first three items of the scale assess for difficulty initiating sleep, difficulty maintaining sleep, and early morning awakening. Individuals are asked to rate the severity of these symptoms over the last two weeks on a scale of $0=$ none, $1=$ mild, $2=$ moderate, $3=$ severe, $4=$ very severe. The next item assesses sleep satisfaction on a five-point scale ranging from $0=$ very satisfied to $4=$ very dissatisfied. The 
next item assesses interference of sleep problems with daytime functioning; the response options are: $0=$ interferes none, $1=$ a little, $2=$ somewhat, $3=$ much; $4=$ very much. The next item assesses for noticeability of sleep issues by others; responses range from $0=$ none, $1=$ barely, $2=$ somewhat, $3=$ much, 4=very much. The final item assesses for how distressed individuals are from their sleep complaints; responses range from $0=$ none, $1=$ a little, $2=$ somewhat, $3=$ much, $4=$ very much (Bastien et al., 2001). The total score is computed as a sum of the items' scores; the total score values vary between 0-28; a value between 0-7 indicates absence of insomnia, 8-14 is indicative of subthreshold insomnia symptoms, 15-21 indicates moderate insomnia, and 22-28 indicates severe insomnia (LeBlanc et al., 2007).

Validity and reliability for the ISI have been established in several studies. Internal consistency reliability has been reported as high with a Cronbach's $\alpha>0.85$ (Ham et al., 2017; Morin, Belleville, Belanger, \& Ivers, 2011). In Chung, Kan, \& Yeung (2011), Cronbach's alpha was .83 , and test-retest reliability was reported as .79. The ISI has also demonstrated convergent validity with sleep diary in Morin et al. (2011), with a r=0.65 reported by LeBlanc et al. (2007).

Impaired daytime functioning. Impaired daytime functioning reflects the subjective experience of daytime sleepiness and is measured by the Epworth Sleepiness Scale (Johns, 1991). In this study, impaired daytime functioning was measured as a continuous variable at the interval level.

The Epworth Sleepiness Scale developed by Johns in 1991 is a self-administered questionnaire that assesses an individual's generalized level of daytime sleepiness. The ESS provides individuals with eight daily experiences (sitting and reading, watching television, sitting inactively in a public place, as a passenger in a car for a continuous hour, lying down for rest mid-afternoon, sitting during a conversation, sitting after lunch (without alcohol), and being in a 
stopped car during traffic), and asks them to rate their likeliness of falling asleep in these situations on a Likert scale with these values: $0=$ never, $1=$ slight chance, $2=$ moderate chance, and $3=$ high chance (Johns, 1991). A total score is computed as the sum of the items' scores and varies between 0 and 24; a score of or above 16 indicates high levels of daytime sleepiness (Johns, 1991). The ESS is valid evidenced by high correlation with other measures of sleepiness such as the multiple sleep latency test (MSLT) and polysomnography (Johns, 1991). Internal consistency is evidenced by a Cronbach's alpha ranging between .80-.88 (Johns, 1992; Wu et al., 2012).

\section{Cardiac Symptoms}

Cardiac symptoms assessed in this study included chest pain, dyspnea, dizziness, syncope, and arrythmia. The frequency and distress with which cardiac symptoms were subjectively experienced were assessed by respective items from the Cardiac Symptom Scale (Ketterer et al., 2008). The Cardiac Symptom Scale was initially adapted by Ketterer et al. (2008), with relevant items derived from the Symptom Checklist-90 (Derogatis, 1997).

Cronbach's alpha has been reported as ranging from .71-.87 and convergent validity between the scale and the Minnesota Multiphasic Inventory has been demonstrated (Shafique, Khalily, \& McHugh, 2017). The scale includes a Likert-Scale questionnaire assessing for both frequency and distress of cardiac symptoms including pain in heart or chest, trouble catching breath, faintness or dizziness, feeling low in energy or slowed down, and heart pounding or racing, over a span of seven days (Fredericks et al., 2016; Ketterer et al., 2008). Response scales for frequency of these cardiac symptoms ranged from $0=$ none of the time, $1=1-2$ times, $2=3-4$ times, $3=4-5$ times, and $4=$ all of the time. Response scales for distress ranged from $0=$ not at all, $1=a$ little bit, $2=$ moderately, $3=$ quite a bit, and $4=$ =xtremely (Ketterer et al., 2008). Total scores are 
calculated with higher scores indicating higher levels of distress and frequency of all cardiac symptoms.

\section{Data Analysis}

All statistical analyses were performed using the IBM SPSS for Windows v25 (SPSS, Inc., Chicago, Ill). Initially, descriptive statistics were used to determine the characteristics of the sample and to assess the variables for violation of assumptions underlying the inferential tests to be used (Gray et al., 2017).

\section{Descriptive Statistics}

For this study, demographic variables included gender, presence of cardiac disease, age, and years of formal education; insomnia symptoms included SOL, WASO, SE, insomnia severity (ISI score), impaired daytime functioning (ESS score); and cardiac symptoms included frequency and distress of chest pain, dyspnea, dizziness, syncope, and arrythmia.

Descriptive statistics were used to characterize the sample on all variables measured and to determine the presence of out-of-range values (i.e. those exceeding minimum and maximum values) and the extent of missing data (Gray et al., 2017; Pallant, 2013).

Categorical variables gender and presence of cardiac disease were examined using frequency distributions. Continuous variables age, years of formal education, SOL, WASO, SE, ISI, ESS, chest pain distress/frequency, dyspnea distress/frequency, dizziness distress/frequency, syncope distress/frequency, and arrythmia distress/frequency, were analyzed using descriptive statistics to examine frequency distribution, measure of central tendency (mean), and dispersion (standard deviation, minimum and maximum values), skewness, and kurtosis (Gray et al., 2017; Pallant, 2013). 
Through examination of the descriptive statistics for each variable, data were assessed for completeness. Variables were to be excluded from further analysis if over $15 \%$ of the data were missing (Fox-Wasylyshyn \& El-Masri, 2005). To address missing data below 15\%, multiple imputation was used, as the literature suggests that attaining a pooled parameter estimate maintains variance in responses (Bannon, 2015; Newman, 2014). Multiple imputation has also been regarded as an unbiased method that is unlikely to increase standard errors associated with hypothesis testing (i.e. Type I and Type II errors).

Of note, variables indicating distress of chest pain, dyspnea, dizziness, syncope, and arrythmia had missing data over $15 \%$. Participants who reported zero for frequency of these symptoms were found to have left the accompanying distress variable blank. To address these missing data, in all cases where a zero was reported in the frequency of a cardiac symptom, a value of 0 was imputed into the accompanying distress variable. This theoretical solution is based on the notion that if a participant does not experience a symptom at any frequency, theoretically, the accompanying distress associated with that symptom cannot be present.

\section{Inferential Statistics}

\section{Differences in presence of chronic insomnia symptoms between individuals with}

CVD and individuals without CVD. To address the first hypothesis of this study, differences between groups (CVD vs. non-CVD) on the presence of insomnia symptoms was examined with the independent samples t-test (Pallant, 2013). This test is the appropriate choice as the dependent variables of chronic insomnia symptoms are continuous variables, and the differences examined between groups occur at one point in time. The group (i.e. CVD or non-CVD) is the categorical independent variable for this test. 


\section{Relationships between chronic insomnia symptoms and cardiac symptoms in}

individuals with CVD and individuals without CVD. To address the second hypothesis, the bivariate relationships between each chronic insomnia symptom and each cardiac symptom, within groups (CVD and non-CVD), was examined with the Pearson $r$ correlation coefficient. This test is the appropriate choice due to the continuous nature of the variables of chronic insomnia symptoms and cardiac symptoms distress and frequency (Pallant, 2013). 


\section{Chapter 4: Results}

This chapter displays the study results. Descriptive findings are presented for the demographic and study variables. This is followed by results of the analyses that addressed the study purposes of 1) examining the difference in chronic insomnia experience between individuals with CVD and individuals without CVD, and 2) examining the relationship between chronic insomnia symptoms and cardiac symptoms within each group (CVD and non-CVD).

\section{Demographic Characteristics of Participants}

A total of 69 participants were included in this secondary analysis. Table 1 summarizes the characteristics of the study participants. The sample included a higher number of women $(n=52,75 \%)$ than men $(n=17,25 \%)$, with an average age of 62.1 years $( \pm 11.0$; range $35-89)$. The years of formal education ranged between 5 and 27, with a mean of $16.6( \pm 4.08)$. Of the total sample, $48 \%(n=33)$ reported a previously diagnosed cardiac disease (Table 1$)$. No significant differences were found between groups on demographic characteristics. 
Table 1

Mean (SD) for Demographic Variables

\begin{tabular}{|c|c|c|c|c|c|c|c|c|c|}
\hline & \multicolumn{6}{|c|}{ Cardiac Presence } & \multicolumn{3}{|c|}{ Total } \\
\hline & \multirow{2}{*}{\multicolumn{3}{|c|}{$\begin{array}{l}\text { Non-Cardiac } \\
\mathrm{N}=36(52 \%)\end{array}$}} & \multirow{2}{*}{\multicolumn{3}{|c|}{$\begin{array}{c}\text { Cardiac } \\
\mathrm{N}=33(48 \%)\end{array}$}} & & & \\
\hline & & & & & & & & & \\
\hline & $\mathrm{M}$ & SD & $\mathrm{n}$ & $\mathrm{M}$ & SD & $\mathrm{n}$ & $\mathrm{M}$ & SD & $\mathrm{N}$ \\
\hline \multirow{3}{*}{$\begin{array}{l}\text { Sex } \\
\text { Male } \\
\text { Female }\end{array}$} & & & 7 & & & 10 & \multirow{3}{*}{-} & \multirow{3}{*}{-} & \multirow{3}{*}{$\begin{array}{c}69 \\
(100 \%)\end{array}$} \\
\hline & - & - & $(19 \%)$ & & & $(30 \%)$ & & & \\
\hline & - & - & $\begin{array}{c}29 \\
(81 \%)\end{array}$ & - & - & $\begin{array}{c}23 \\
(70 \%)\end{array}$ & & & \\
\hline Age & 58.25 & 10.63 & 36 & 66.34 & 9.99 & 33 & 62.06 & 10.95 & 69 \\
\hline $\begin{array}{l}\text { Years of } \\
\text { Formal } \\
\text { Education }\end{array}$ & 16.75 & 3.91 & 36 & 16.52 & 4.32 & 33 & 16.64 & 4.08 & 69 \\
\hline
\end{tabular}

\section{Experience of Chronic Insomnia Symptoms}

Descriptive findings for all symptoms of chronic insomnia, as reported by all participants, are in Table 2. No missing data or out of range values were noted on these variables. In examining the variables for normality, an outlier was noted in SOL through examination of high kurtosis $(\mathrm{k}=24.84)$, indicating a heavy-tailed distribution. Additionally, as is common among variables measured in the social sciences, ESS $\left(\gamma_{1}=.75\right)$, SOL $\left(\gamma_{1}=4.31\right)$, and WASO $\left(\gamma_{1}=1.66\right)$ were noted to have a positive skew, indicating that the majority of values are distributed in the lower range (Pallant, 2013, p. 214). However, the literature suggests that both the independent samples t-test and the Pearson $\mathrm{r}$ correlation hold a high level of rigour (i.e. are robust) and thereby remain appropriate for the analyses addressing the study hypotheses (Cohen, 1988, p. 19, 75; Green \& Salkind, 2008, p. 176; Havlicek \& Peterson, 1977). Additionally, in examining Levene's Test for Equality of Variance, all chronic insomnia variables except WASO ( $p=.01)$ 
met the assumption of equal variance; however, in case the assumption of equal variance was not met, the appropriate formula for t-test was used to compensate for this violation (Pallant, 2013, p. 250).

The mean score for difficulty initiating sleep, as measured through SOL (in minutes), indicates that on average, it took participants approximately 25 minutes to fall asleep; the wide range (1.64 to 584.71 minutes) suggests that the amount of time it took participants to fall asleep varied greatly. The mean score for difficulty maintaining sleep, assessed through WASO (in minutes) also indicated that participants stayed awake for more than one hour across all awakenings.

The mean score for sleep efficiency $(64.34 \%)$ was lower than the cut-off value $(>80 \%)$ for adequate sleep efficiency, reflecting poor sleep. Additionally, the mean score for perceived insomnia severity, assessed through the total scores on the ISI, indicated that on average the participants experienced clinical insomnia of moderate severity. Finally, participants' mean score on impaired daytime functioning fell below the cut-off point $(>16)$ on the ESS, indicating overall limited impairment in daytime functioning. 
Table 2

Mean (SD) for Chronic Insomnia Symptoms

\begin{tabular}{|c|c|c|c|c|c|c|c|c|}
\hline & \multicolumn{4}{|c|}{ Cardiac Presence } & \multicolumn{2}{|c|}{ Total } & \multirow{3}{*}{ Min } & \multirow{3}{*}{ Max } \\
\hline & \multicolumn{2}{|c|}{$\begin{array}{l}\text { Non-Cardiac } \\
\mathrm{N}=36(52 \%)\end{array}$} & \multicolumn{2}{|c|}{$\begin{array}{c}\text { Cardiac } \\
\mathrm{N}=33(48 \%)\end{array}$} & \multicolumn{2}{|c|}{$\begin{array}{c}\text { Total } \\
\mathrm{N}=69(100 \%)\end{array}$} & & \\
\hline & $M$ & SD & $\mathrm{M}$ & SD & $\mathrm{M}$ & SD & & \\
\hline SOL & 55.94 & 103.09 & 54.52 & 53.20 & 55.26 & 82.48 & 1.64 & 584.71 \\
\hline WASO & 52.02 & 31.15 & 82.05 & 56.73 & 66.38 & 47.36 & .00 & 262.86 \\
\hline SE & 67.70 & 17.06 & 60.68 & 16.44 & 64.34 & 17.01 & .00 & 88.16 \\
\hline ISI & 17.60 & 4.80 & 18.84 & 4.41 & 18.20 & 4.63 & 8.00 & 28.00 \\
\hline ESS & 6.81 & 4.84 & 5.58 & 4.84 & 6.22 & 4.84 & .00 & 19.00 \\
\hline
\end{tabular}

\section{Experience of Cardiac Symptoms}

Descriptive findings for cardiac symptoms can be found in Table 3. A missing datum was noted in the variable arrythmia frequency $(1.45 \%)$ and was replaced using multiple imputation prior to inferential statistics. Additionally, all participants rated the frequency of occurrence but some who did not experience a symptom did not rate its distress; in cases where frequency was rated as 0 , a value of 0 was imputed for the corresponding distress variable.

Chest pain frequency $\left(\gamma_{1}=2.29\right)$, dyspnea frequency $\left(\gamma_{1}=2.49\right)$, dyspnea distress $\left(\gamma_{1}=1.24\right)$, dizziness frequency $\left(\gamma_{1}=1.36\right)$, dizziness distress $\left(\gamma_{1}=.57\right)$, arrythmia frequency $\left(\gamma_{1}=1.69\right)$, and arrythmia distress $\left(\gamma_{1}=5.22\right)$ were noted to have a positive skew, indicating that the majority of values were in the lower range (Table 3). As the cardiac symptom variables were included in the correlation analysis, it is of note that although these variables do not meet the assumption of normality, it has been found that the Pearson $r$ correlation coefficient is robust enough to 
overcome extreme violations of the normality assumption (Cohen, 1988, p. 75; Havlicek \& Peterson, 1977).

On average, participants reported low frequency (up to 1-2 times over a seven-day period) in the experience of all cardiac symptoms (chest pain, dyspnea, dizziness, syncope, and arrythmia). Additionally, the mean score for distress with the same symptoms indicated low-tomoderate levels. This indicates that regardless of the low frequency with which participants experienced the cardiac symptoms over the seven-day period, they perceived this experience as low-to-moderately distressful. Additionally, individuals in the cardiac group, on average, had higher mean scores for frequency and distress associated with all cardiac symptoms, excluding syncope frequency which was not reported in either group, and syncope distress which was not reported in the cardiac group. Overall, the experience of cardiac symptoms, both in frequency and distress is low in this sample. 
Table 3

Mean (SD) for Cardiac Symptoms

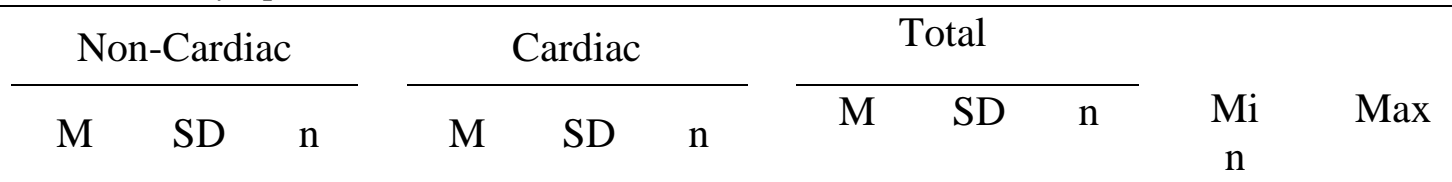

\begin{tabular}{|c|c|c|c|c|c|c|c|c|c|c|c|}
\hline $\begin{array}{l}\text { Chest } \\
\text { Pain } \\
\text { Frequency }\end{array}$ & .17 & .45 & 36 & .73 & 1.07 & 33 & .43 & .85 & 69 & .00 & 4.00 \\
\hline $\begin{array}{l}\text { Chest } \\
\text { Pain } \\
\text { Distress }\end{array}$ & .31 & .82 & 36 & .85 & 1.12 & 33 & .57 & 1.01 & 69 & .00 & 3.00 \\
\hline $\begin{array}{l}\text { Dyspnea } \\
\text { Frequency }\end{array}$ & .19 & .52 & 36 & .36 & .70 & 33 & .28 & .62 & 69 & .00 & 3.00 \\
\hline $\begin{array}{l}\text { Dyspnea } \\
\text { Distress }\end{array}$ & .22 & .68 & 36 & .36 & .86 & 33 & .29 & .77 & 69 & .00 & 3.00 \\
\hline $\begin{array}{l}\text { Dizziness } \\
\text { Frequency }\end{array}$ & .56 & .88 & 36 & .61 & .86 & 33 & .58 & .86 & 69 & .00 & 3.00 \\
\hline $\begin{array}{l}\text { Dizziness } \\
\text { Distress }\end{array}$ & .56 & 1.05 & 36 & .67 & 1.02 & 33 & .61 & 1.03 & 69 & .00 & 4.00 \\
\hline $\begin{array}{l}\text { Syncope } \\
\text { Frequency }\end{array}$ & .00 & .00 & 36 & .00 & .00 & 33 & .00 & .00 & 69 & .00 & .00 \\
\hline $\begin{array}{l}\text { Syncope } \\
\text { Distress }\end{array}$ & .03 & .17 & 36 & .00 & .00 & 33 & .01 & .12 & 69 & .00 & 1.00 \\
\hline $\begin{array}{l}\text { Arrythmia } \\
\text { Frequency }\end{array}$ & .29 & .66 & 36 & .76 & .96 & 33 & .52 & .85 & 69 & .00 & 3.00 \\
\hline $\begin{array}{l}\text { Arrythmia } \\
\text { Distress }\end{array}$ & .42 & 1.00 & 36 & .85 & 1.12 & 33 & .62 & 1.07 & 69 & .00 & 4.00 \\
\hline
\end{tabular}

Differences Between Individuals with CVD and Individuals without CVD on Chronic Insomnia Symptoms

The mean scores on chronic insomnia symptoms for the two groups of participants that is, with and without CVD, are presented in Table 2, and the results of the group comparison are in Table 4. As presented in Table 4, the effect sizes (ES) suggest that the between-group 
differences for most symptoms of chronic insomnia were small or moderate. The largest ES and a statistically significant difference was found between those with CVD and those without CVD in WASO $(t=-2.69, p=.01, \mathrm{~d}=.66)$, indicating that individuals with CVD took approximately 30 minutes longer to regain sleep once awakened (difficulty maintaining sleep) across all awakenings, than their counterparts. No other statistically significant differences were found; however, the ES for SE indicates that a moderate difference $(\mathrm{d}=.42)$ was found between individuals with CVD and individuals without CVD in their sleep efficiency $(t=1.74 ; p=.09)$. On average, individuals with CVD had a 7\% lower SE than their counterparts. The ES for SOL, ISI, and ESS were small.

Table 4

Results of t-test for chronic insomnia symptoms by CVD status

\begin{tabular}{lccccc}
\hline & $\begin{array}{c}95 \% \text { CI for Mean } \\
\text { Difference }\end{array}$ & $\mathrm{t}$ & $\mathrm{df}$ & $\mathrm{p}$ & $\mathrm{ES}$ \\
\hline SOL & $-38.56,41.39$ & .07 & 67 & .94 & .02 \\
WASO & $-52.46,-7.61$ & -2.69 & 48.73 & .01 & .66 \\
SE & $-1.04,15.10$ & 1.74 & 67 & .09 & .42 \\
ISI & $-3.47, .97$ & -1.12 & 67 & 27 & .27 \\
ESS & $-1.10,3.56$ & 1.06 & 67 & .30 & .23 \\
\hline
\end{tabular}

\section{Relationships Between Chronic Insomnia and Cardiac Symptoms Within Groups}

In participants without CVD (n=36), several cardiac symptoms were associated with insomnia symptoms (Table 5). Severity of insomnia, as measured by the ISI, was positively and moderately associated with chest pain distress $(r=.35, p=.04)$, dizziness frequency $(r=.41, p=.01)$ 
and distress $(r=.42, p=.01)$, and arrythmia distress $(r=.35, p=.04)$. This indicates that participants without CVD who experienced a high insomnia severity, also reported greater distress associated with the experience of chest pain and heart racing, as well as frequency and distress associated with the experience of dizziness. In addition, impaired daytime functioning, as measured through ESS total score was positively and moderately associated with chest pain frequency $(r=.36$, $p=.03)$ and distress $(r=.45, p=.01)$, as well as dizziness $(r=.36, p=.03)$ and arrythmia distress $(r=.41, p=.01)$. This indicates that participants who experienced greater daytime sleepiness, also reported more frequent experience of chest pain, as well as more distress associated with chest pain, dizziness, and arrythmia.

A few associations were significant at $p=.07-.08$ in this group. Insomnia severity was moderately and positively associated with syncope distress $(r=.30, p=.08)$, indicating that participants who reported higher severity of insomnia, also reported greater distress associated with the experience of fainting. In addition, impaired daytime functioning was positively and moderately associated with dizziness frequency $(r=.30, p=.07)$, indicating that individuals who reported increased daytime sleepiness, also reported increased frequency of dizziness over a 7day period.

In participants with CVD ( $=33)$, one statistically significant association was found (Table 6). A medium-sized negative correlation was found between insomnia severity and dyspnea frequency $(r=-.46, p=.01)$ indicating that participants who reported higher insomnia severity, reported a lower frequency of difficulty breathing over a 7-day period. A moderately positive association approaching statistical significance was also found between insomnia severity and arrythmia distress $(r=.31, p=.08)$, indicating that individuals who reported high severity of insomnia also reported greater distress associated with the experience of heart racing. 
Of note, none of the participants from the total sample expressed any frequency of syncope, and none of the participants with CVD expressed any distress from syncope, therefore the correlation of these cardiac symptoms with chronic insomnia symptoms could not be estimated as shown in Tables 5 and 6.

Table 5

Results of Pearson r Correlation for Chronic Insomnia Symptoms and Cardiac Symptoms in Participants with No Cardiac Disease

\begin{tabular}{|c|c|c|c|c|c|c|c|c|c|c|}
\hline & \multicolumn{2}{|c|}{ SOL } & \multicolumn{2}{|c|}{ WASO } & \multicolumn{2}{|c|}{$\mathrm{SE}$} & \multicolumn{2}{|c|}{ ISI } & \multicolumn{2}{|c|}{ ESS } \\
\hline & $\mathrm{r}$ & $\mathrm{p}$ & $\mathrm{r}$ & $\mathrm{p}$ & $\mathrm{r}$ & $p$ & $\mathrm{r}$ & $\mathrm{p}$ & $\mathrm{r}$ & $\mathrm{p}$ \\
\hline $\begin{array}{l}\text { Chest } \\
\text { Pain } \\
\text { Frequency } \\
\mathrm{N}=36\end{array}$ & -.11 & .52 & .21 & .22 & .17 & .32 & .23 & .17 & .36 & .03 \\
\hline $\begin{array}{l}\text { Chest } \\
\text { Pain } \\
\text { Distress } \\
\mathrm{N}=36\end{array}$ & -.12 & .51 & .18 & .30 & .16 & .37 & .35 & .04 & .45 & .01 \\
\hline $\begin{array}{l}\text { Dyspnea } \\
\text { Frequency } \\
\mathrm{N}=36\end{array}$ & -.12 & .49 & -.01 & .98 & .23 & .18 & .08 & .65 & .09 & .59 \\
\hline $\begin{array}{l}\text { Dyspnea } \\
\text { Distress } \\
\mathrm{N}=36\end{array}$ & -.20 & .51 & -.02 & .92 & .27 & .18 & .14 & .41 & .14 & .40 \\
\hline $\begin{array}{l}\text { Dizziness } \\
\text { Frequency } \\
\mathrm{N}=36\end{array}$ & .07 & .67 & .10 & .58 & -.09 & .62 & .41 & .01 & .30 & .07 \\
\hline $\begin{array}{l}\text { Dizziness } \\
\text { Distress } \\
\mathrm{N}=36\end{array}$ & .17 & .34 & .19 & .28 & -.12 & .47 & .42 & .01 & .36 & .03 \\
\hline $\begin{array}{l}\text { Syncope } \\
\text { Frequency } \\
\mathrm{N}=36\end{array}$ & - & - & - & - & - & - & - & - & - & - \\
\hline $\begin{array}{l}\text { Syncope } \\
\text { Distress } \\
\mathrm{N}=36\end{array}$ & .18 & .30 & -.02 & .93 & -.13 & .46 & .30 & .08 & .08 & .65 \\
\hline $\begin{array}{l}\text { Arrythmia } \\
\text { Frequency } \\
\mathrm{N}=36\end{array}$ & -.15 & .36 & -.07 & .68 & .22 & .21 & .21 & .22 & .19 & .27 \\
\hline $\begin{array}{l}\text { Arrythmia } \\
\text { Distress } \\
\mathrm{N}=36\end{array}$ & -.13 & .44 & -.02 & .93 & .19 & .27 & .35 & .04 & .41 & .01 \\
\hline
\end{tabular}


Table 6

Results of Pearson r Correlation for Chronic Insomnia Symptoms and Cardiac Symptoms in Participants with Cardiac Disease

\begin{tabular}{|c|c|c|c|c|c|c|c|c|c|c|}
\hline & \multicolumn{2}{|c|}{ SOL } & \multicolumn{2}{|c|}{ WASO } & \multicolumn{2}{|c|}{$\mathrm{SE}$} & \multicolumn{2}{|c|}{ ISI } & \multicolumn{2}{|c|}{ ESS } \\
\hline & $\mathrm{r}$ & $\mathrm{p}$ & $r$ & $\mathrm{p}$ & $r$ & $\mathrm{p}$ & $r$ & $\mathrm{p}$ & $r$ & $\mathrm{p}$ \\
\hline $\begin{array}{l}\text { Chest } \\
\text { Pain } \\
\text { Frequency } \\
\mathrm{N}=33\end{array}$ & -.19 & .27 & -.06 & .76 & .13 & .49 & .10 & .58 & .23 & .20 \\
\hline $\begin{array}{l}\text { Chest } \\
\text { Pain } \\
\text { Distress } \\
\mathrm{N}=33\end{array}$ & -.15 & .39 & -.08 & .69 & .11 & .53 & -.14 & .44 & .25 & .17 \\
\hline $\begin{array}{l}\text { Dyspnea } \\
\text { Frequency } \\
\mathrm{N}=33\end{array}$ & -.18 & .32 & .03 & .87 & .16 & .38 & -.46 & .01 & -.06 & .76 \\
\hline $\begin{array}{l}\text { Dyspnea } \\
\text { Distress } \\
\mathrm{N}=33\end{array}$ & -.06 & .73 & .21 & .24 & .05 & .76 & -.01 & .96 & .14 & .45 \\
\hline $\begin{array}{l}\text { Dizziness } \\
\text { Frequency } \\
\mathrm{N}=33\end{array}$ & .05 & .79 & .10 & .59 & -.01 & .97 & .19 & .29 & .12 & .52 \\
\hline $\begin{array}{l}\text { Dizziness } \\
\text { Distress } \\
\mathrm{N}=33\end{array}$ & .09 & .64 & .09 & .63 & -.09 & .63 & .29 & .11 & -.09 & .61 \\
\hline $\begin{array}{l}\text { Syncope } \\
\text { Frequency } \\
\mathrm{N}=33\end{array}$ & - & - & - & - & - & - & - & - & - & - \\
\hline $\begin{array}{l}\text { Syncope } \\
\text { Distress } \\
\mathrm{N}=33\end{array}$ & - & - & - & - & - & - & - & - & - & - \\
\hline $\begin{array}{l}\text { Arrythmia } \\
\text { Frequency } \\
\mathrm{N}=33\end{array}$ & .14 & .44 & .10 & .57 & -.19 & .29 & .16 & .37 & -.19 & .29 \\
\hline $\begin{array}{l}\text { Arrythmia } \\
\text { Distress } \\
\mathrm{N}=33\end{array}$ & .19 & .29 & .14 & .42 & -.26 & .14 & .31 & .08 & -.22 & .22 \\
\hline
\end{tabular}




\section{Chapter 5: Discussion}

This chapter provides a brief outline of the purpose of this study, followed by a discussion of the main findings, strengths and limitations, as well as significance of the study and future implications.

\section{Study Purpose}

The purpose of this study was twofold. The first aim was to compare the experience of chronic insomnia symptoms, including difficulty initiating sleep, difficulty maintaining sleep, sleep efficiency, insomnia severity, and daytime sleepiness, between individuals with CVD and individuals without CVD. The second aim of this study was to examine the relationship between the experience of chronic insomnia symptoms and of cardiac symptoms, assessed through frequency and distress of chest pain, dyspnea, dizziness, syncope, and arrythmia, within individuals with CVD and individuals without CVD.

\section{Main Findings}

\section{Hypothesis 1: Difference in Experience of Chronic Insomnia Symptoms between Individuals with CVD and Individuals without CVD}

The findings of the t-test indicated that there is a difference in the experience of one chronic insomnia symptom (difficulty maintaining sleep) between individuals who have and do not have a diagnosis of CVD. Individuals with CVD were found to require on average 30 minutes more to regain sleep across all awakenings, compared to their counterparts. Additionally, a finding approaching statistical significance demonstrated that individuals with CVD, on average, had a $7 \%$ lower sleep efficiency compared to their counterparts. These findings may be explained by the older mean age found among the CVD group $(66, \pm 10)$ when 
compared to the non-CVD group $(58, \pm 11)$. Due to decreases in core body temperature, levels of melatonin, and an altered circadian rhythm, evidence suggests that older adults (>65y) experience greater difficulty maintaining sleep and longer periods for each awakening when compared to younger adults (<65y) (Ancoli-Israel, Ayalon, \& Salzman, 2008; Crowley, 2011; Sidani et al., 2018). This greater experience of sleep fragmentation and waking after sleep onset ultimately results in decreases in sleep efficiency in the older adult population (Ancoli-Israel et al., 2008; Crowley, 2011; Sidani et al., 2018). Another possible explanation for the findings of increased awakening after sleep onset among the CVD group may be due to paroxysmal nocturnal dyspnea commonly found in the cardiac disease of heart failure (Kasper \& Knudson, 2010). Upon a postural change, excess fluid from lower extremities may return to the heart which, unable to accommodate this shift, leads to fluid buildup in the lungs and subsequent multiple awakenings with shortness of breath (Kasper \& Knudson, 2010).

Additionally, there was no significant difference in the experience of sleep onset latency between individuals with CVD and individuals without CVD in this study, which is contrary to previous evidence (Y. Li et al., 2014; Mallon et al., 2002), however, it is of importance to note that evidence suggests that difficulty initiating sleep (SOL) is a sleep symptom found more commonly among young and middle aged adults, which does not reflect the mean age of the CVD population in this study $(66, \pm 10)$.

Overall, the findings of this study corroborate previous findings regarding the higher incidence of chronic insomnia symptoms in the CVD population (Edéll-Gustaffson, 2002; Johansson et al., 2010; Taylor et al., 2007). Particularly, the findings are consistent with those of Johansson et al. (2010), who through similar sample size ( $\mathrm{n}=36$ per group) and measurement methods (Uppsala Sleep Inventory and Epworth Sleepiness Scale), found that individuals with 
heart failure had more difficulty maintaining sleep $(72 \%$ vs. $50 \%, p=.05)$ than individuals without heart failure. The findings are also comparable to those of Edéll-Gustaffson (2002), who examined insufficient sleep in 44 men with CVD and found that difficulty maintaining sleep was the highest reported sleep problem (40.9\% of sample).

These findings thereby hold clinical significance not only in their corroboration with previous evidence that chronic insomnia symptoms are experienced more commonly among individuals with CVD, but also in that the experience of both difficulty maintaining sleep and low sleep efficiency has been associated with negative effects on memory, concentration, sleepiness, and overall quality of life (Ancoli-Israel et al., 2008; Crowley, 2011; Sidani et al., 2018). Experience of difficulty maintaining sleep is also of clinical importance due to its association with increased risk of acute myocardial infarction (Laugsand et al., 2011; Meisinger et al., 2007). Additionally, in women, frequent awakening at night is also associated with greater experience of cardiac symptoms including chest pain and arrythmia, both of which have been associated with decreased quality of life (Asplund \& Aberg, 1998; Fang \& Bjorkman, 2001). Poor sleep efficiency $(<85 \%)$ has also been positively associated with self-reported negative emotions and slower reaction times (Eiman, Weinstein, \& Kop, 2017). Particularly in the cardiac population, the experience of sleep problems has been associated with a $45 \%$ increased incidence of morbidity and mortality attributed to CVD events (M. Li et al., 2014; Sofi et al., 2012).

\section{Hypothesis 2: Relationship between Chronic Insomnia Symptoms and Experience of Cardiac Symptoms in Individuals with CVD and Individuals without CVD}

Individuals with CVD. Findings of this study indicate a moderate and positive association between insomnia severity and arrythmia distress. Evidence suggests that experience of insomnia is associated with distressing experiences of arrythmia described by participants as 
heart pounding experienced randomly throughout the night (Broström et al., 2001). These experiences are clinically significant as they have been described by participants as contributing to increased levels of anxiety regarding illness progression as well as daytime impairments in cognitive function including sleepiness, listlessness, and inability to concentrate or enjoy daily experiences with family and friends (Broström et al., 2001). In this study, this association was found to be approaching statistical significance $(p=.08)$, however, is considered clinically significant due to the moderate-sized effect.

Additionally, specific findings counter the second hypothesis of this study suggesting participants with an increased self-perception of insomnia severity had a decreased experience of dyspnea (Table 6). In reviewing previous studies, dyspnea has been found to have a positive relationship with disturbed sleep; participants with CVD reported that the experience of insomnia is associated with difficulty breathing and shortness of breath during the night as sleep is attempted, particularly when lying flat (Broström et al., 2001). Dyspnea has also been described as a cardinal sign of heart failure (Rials et al., 2017). Discrepancy in the result found in this study may be due to the adaptive behaviours of individuals with CVD. Rials et al. (2017) suggest that individuals with worsening HF compensate for orthopnea and paroxysmal nocturnal dyspnea by increasing the angle with which they attempt to sleep (i.e. increasing the number of pillows behind them). As it pertains to the CVD population, upright position decreases dyspnea experience (Grubb, 2002; Mansen \& Gabiola, 2015); therefore, due to lived-experience with CVD, participants in this study may have instinctively attempted to sleep in a seated position, thereby negating the experience of paroxysmal nocturnal dyspnea and decreasing the incidence of difficulty breathing found in this study. To further explore this relationship, future research could benefit from including a question regarding positioning with sleep, along with an 
examination of type of CVD (HF vs. other CVD disorders), and onset of cardiac illness

experience to evaluate adaptive behaviours over time.

Individuals without CVD. In individuals without CVD, insomnia severity was found to be positively and moderately associated with distress from chest pain, dizziness, syncope, and arrythmia, as well as frequency of dizziness (Table 5). Daytime sleepiness was also found to be positively and moderately associated with distress from chest pain, dizziness, and arrythmia, as well as frequency of chest pain and dizziness (Table 5).

These results are clinically significant not only for their effects on quality of life and health, but also on the burden they place on the healthcare system. For instance, individuals experiencing chest pain have been found to have frequent ER visits with multiple admissions and readmissions (Fang \& Bjorkman, 2001). This increase in healthcare use has also been found among individuals with frequent syncopial spells; $0.8 \%$ of all ER visits per year can be attributed to syncope, with $32 \%$ of these visits resulting in hospital admission with a subsequent $\$ 3.8$ billion expenditure (Sun, 2013). In addition to healthcare associated costs, experience of cardiac symptoms including chest pain, syncope, and dizziness have been associated with decreased quality of life and health-related quality of life (Brown et al., 1999; Husser et al., 2012; Ten Voorde et al., 2012). Presence of chest pain has also been associated with anxiety, depression, and activity limitation leading to inability to work (Fang \& Bjorkman, 2001). This anxiety, depression and inability to work is also found in individuals who suffer from syncope due to restrictions placed on driving and use of heavy machinery (Rose, Koshman, Spreng, \& Sheldon, 2000; Sun, 2013).

Although evidence is limited on this topic, positive associations have been found between poor sleep and frequent nocturnal awakenings and both arrythmia and chest pain (Asplund, 2003; 
Asplund \& Aberg, 1998). Findings of previous studies also suggest that arrythmia and chest pain are more common amongst those with greater experience of daytime sleepiness (Asplund \& Aberg, 1998). Additionally, a positive association has also been demonstrated between insomnia severity (measured with the validated ISI) and chest pain (Belleville et al., 2014).

The findings of this secondary analysis not only corroborate the evidence found in each of these published studies but have also extended beyond those of previous studies within the literature. These additional associations may result from the expansive conceptualization of cardiac symptoms in this study. Previous studies have mainly focused solely on presence of chest pain, arrythmia, and dyspnea (Asplund, 2003; Asplund \& Aberg, 1998; Belleville et al., 2014) whereas in this study, cardiac symptoms also included dizziness and syncope, as well as an examination of both frequency and distress for each cardiac symptom. The increased number of associations found here can thereby be used as a steppingstone with which to study chronic insomnia and cardiac symptom associations in future studies.

\section{Strengths}

A major strength of this study is in the use of validated and reliable measures assessing the experience of chronic insomnia (ISI, ESS, and DSD). A limitation found in previous studies examining chronic insomnia is the use of single-Likert scale questions (Canivet et al., 2014; Laugsand et al., 2014; Y. Li et al., 2014; Mallon et al., 2002). With these single-item scales, previous studies have jeopardized construct validity by operationalizing the multi-faceted concept of insomnia into a single item. Additionally, use of highly reliable measures increases the power of the study to detect significant between-group differences and relationships among variables, while demonstrated validity increases the confidence with which findings from the analyses can be attributed to the concepts being measured (Gray et al., 2017). 
The second strength of this study lies in the incorporation of a strong and broad conceptual framework, developed using theoretical, conceptual, and research-based literature. In the conceptualization of chronic insomnia, this study used several symptoms such as difficulty initiating sleep, difficulty maintaining sleep, early morning awakenings, sleep efficiency, total insomnia severity, and daytime sleepiness. In examining cardiac symptoms, this study used both frequency and distress associated with cardiac symptoms including chest pain, dyspnea, dizziness, syncope, and arrythmia. Previous studies examining both chronic insomnia and cardiac symptoms have looked at fewer symptoms in their conceptualization, thereby narrowing the experience of the concepts in their respective populations. By including such an inclusive conceptualization of the concepts at hand, this study allows for greater validity in the findings of the analyses completed.

Finally, a strength of this study lies in the use of random sampling to attain the comparison group (non-CVD) from the total sample of the original study. To attain this sample, systematic sampling was used wherein all participants (without-CVD) had an equal opportunity to be included in this study. This use of random sampling allows for greater external validity in that results can be generalized to the chronic insomnia population at large (Gray et al., 2017).

\section{Limitations}

The first limitation of this study is the small sample size $(n=69)$. With a sample size of approximately 30 per group, in completing a power analyses with a power of .80 and $p>.05$, this

study was able to detect moderate to large differences/relationships (Cohen, 1988; Hertzog, 2008). However, as this study examines relationships that are not well studied, a small sample size was appropriate for this preliminary explorative study to determine whether a relationship exists between chronic insomnia symptoms and cardiac symptoms (Hacksaw, 2008). This small- 
scale study can thereby be used as a hypothesis generating study for further confirmatory and larger-scale studies examining these relationships (Hacksaw, 2008).

Another limitation of this study is in the structure of the Cardiac Symptom Scale. During preliminary analysis, it was noted that items assessing distress with the cardiac symptoms had missing data for greater than $15 \%$ of the participants. When examining frequency tables for the data, it was noted that distress data were missing only for participants who reported no experience (frequency) of the corresponding cardiac symptom. A proposed explanation for this occurrence is that as participants were not provided with a written cue to answer all questions, some participants who did not experience a cardiac symptom (frequency) instinctively chose to disregard the associated distress question, as it is logically improbable to experience distress associated with a non-existent symptom experience.

To address this concern, a value of zero was imputed for each missing value (distress) that had a corresponding zero value in the frequency field. In the future, the Cardiac Symptom Scale must be reassessed for structure, clarity, and readability, to ensure that participants are prompted to answer each and every question on the scale. In ensuring that the scale is clear in this regard, content validity can subsequently be increased (Gray et al., 2017).

\section{Significance}

Chronic insomnia is a sleep disorder that affects $10-15 \%$ of the world population (Ciano et al., 2017; Thase, 2005). Individuals who experience chronic insomnia have been found to have a twofold increase in practitioner visits and hospitalizations, along with depression, anxiety, poor work performance, absenteeism, and decreased quality of life (Ketterer et al., 2008; Maness \& Khan, 2015; Redeker et al., 2010; Sorscher, 2017; Thase, 2005). 
In examining differences in the experience of chronic insomnia symptoms between individuals with CVD and individuals without CVD, this study was able to further solidify the evidence regarding this topic, demonstrating that there is a difference experienced in chronic insomnia symptoms between the two groups of individuals, which is important as chronic insomnia is associated with $45 \%$ increased morbidity and mortality from CVD events (Sofi et al., 2012).

The findings of this study also indicated a positive correlation between chronic insomnia symptoms and cardiac symptoms which is valuable in adding to the limited literature and evidence examining chronic insomnia and cardiac symptoms concurrently. In completing a literature review, it was noted that a gap exists, particularly in the examination of chronic insomnia and cardiac symptoms, in any population. This study examined relationships between these variables not only in individuals with chronic insomnia, but also among individuals who are diagnosed with CVD.

Using the findings of this study as a stepping stone, in addition to continuing research on CVD risk factors such as chronic insomnia, further studies can be developed to examine how best to address the experience of chronic insomnia and cardiac symptoms, through interventions within the scope of practice for the nursing profession, with the aim of decreasing the progression and prevalence of CVD in the Canadian population. Additional replication of the study with different populations should also be done in order to increase generalizability of results to other populations. 


\section{Future Implications}

Literature suggests that currently, in addition to the traditional risk factors of sex (male), advanced age, family history, hypertension history, diabetes, and obesity, the most commonly assessed risk factors for CVD include smoking, BMI, diet, blood pressure, physical activity, fasting glucose, and total cholesterol (Khambhati et al., 2018). However, chronic insomnia is an easily identifiable risk factor for the development of CVD and can thereby be included as a component of the assessment provided for individuals at risk for CVD. In examining the experience of chronic insomnia prior to CVD development, nurse-led treatments can be implemented in a prompt manner with the goal of decreasing progression and overall CVD incidence in the Canadian population.

Additionally, for individuals diagnosed with chronic insomnia, evidence suggests that nurse-led treatments for insomnia such as stimulus control therapy (SCT), sleep restriction therapy (SRT), and cognitive behavioural therapy for insomnia (CBT-I) are highly effective as first line therapies (Schutte-Rodin et al., 2008). Use of such therapies as a component of cardiac rehabilitation can potentially provide undoubted value for individuals diagnosed with CVD, as these therapies encompass cognitive and behavioural components rather than pharmacological therapies, the addition of which can contribute to polypharmacy, and subsequent inappropriate medication use, low adherence, and adverse effects in the CVD population (Volpe, Chin, \& Paneni, 2010).

According to the Standards for the Provision of Cardiovascular Rehabilitation in Ontario (Cardiac Care Network [CCN], 2014), cardiac rehabilitation must encompass components of health behaviour change and education, cardiovascular risk factor management, and cardioprotective pharmacological therapies. A key component of these programs is the 
personalized and targeted approach to modification of health behaviours, including factors such as physical activity, healthy nutrition, decreased tobacco use, and treatment for psychological and psychosocial impairments (CCN, 2014). To decrease the burden of CVD on individuals' quality of life and overall health, as well as to strengthen the evidence on this topic, future experimental research is needed to examine the difference in the experience of cardiac symptoms, insomnia, and variables such as quality of life prior to and following the implementation of nurse-led behavioural and cognitive therapies for insomnia as a component of cardiovascular risk factor management and health behaviour change and education. Additionally, through measurement of cardiac symptoms in this population, future research can also examine the real-time effects of this nurse-led treatment on overall cardiovascular disease experience, as well as associations between decreases in cardiac symptom experience with overall quality of life in the cardiac population.

In examining treatment in this population, it is also important to consider variables such as cardiac disease class (NYHA class), specific diagnosis of cardiac disease (i.e. heart failure versus coronary artery disease), and length of time since cardiac disease onset. As most studies examining the provision of cognitive and behavioural therapies are completed among a generalized population, examining the relationships between chronic insomnia and these particular nuances of CVD, in the context of cardiac rehabilitation, will provide an indication as to whether nurse-led treatment is effective in decreasing symptom experience (chronic insomnia and cardiac symptoms) not only in the CVD population as a whole, but among the many subsets of the CVD population in particular. Overall, examining treatment within the context of chronic insomnia and cardiac symptoms in the CVD population will allow for future nurse researchers to 
affect change in not only progression to, or regression of CVD, but in the mortality associated with CVD in the Canadian population. 


\section{References}

Ancoli-Israel, S., Ayalon, L., \& Salzman, C. (2008). Sleep in the elderly: Normal variations and common sleep disorders. Harvard Review of Psychiatry, 16(5), 279-286.

doi:10.1080/10673220802432210

Asplund, R. (2003). Nightmares, sleep and cardiac symptoms in the elderly. The Netherlands Journal of Medicine, 61(7), 257-261. Retrieved from

http://www.njmonline.nl/getpdf.php?id=28

Asplund, R., \& Aberg, H. E. (1998). Sleep and cardiac symptoms amongst women aged 40-64 years. Journal of Internal Medicine, 243(3), 209-213. doi:10.1046/j.13652796.1998.00276.x

Asplund, R., \& Aberg, H. E. (2003). Nightmares, cardiac symptoms and the menopause. Climacteric, 6, 314-320. doi:10.1080/cmt.6.4.314.320

Bannon, W. (2015). Missing data within a quantitative research study: How to assess it, treat it, and why you should care. Journal of the American Association of Nurse Practitioners, 27(4), 230-232. doi:10.1002/2327-6924.12208

Bastien, C. H., Vallières, A., \& Morin, C. M. (2001). Validation of the Insomnia Severity Index as an outcome measure for insomnia research. Sleep Medicine, 2(4), 297-307. doi:10.1016/S1389-9457(00)00065-4

Belleville, G., Foldes-Busque, G., Poitras, J., Chauny, J-M., Diodati, J. G., Fleet, R., \& Marchand, A. (2014). Insomnia in patients with unexplained chest pain. Psychomatics, 55(5), 458-468. doi:10.1016/j.psym.2013.12.004 
Bertisch, S. M., Pollock, B. D., Mittleman, M. A., Buysse, D. J., Bazzano, L. A., Gottlieb, D. J., \& Redline, S. (2018). Insomnia with objective short sleep duration and risk of incident cardiovascular disease and all-cause mortality: Sleep Heart Health study. Sleep, 41(6), 1-9. doi:https://doi.org/10.1093/sleep/zsy047

Broström, A., Strömberg, A., Dahlström, U., Fridlund, B. (2001). Patients with congestive heart failure and their conceptions of their sleep situation. Journal of Advanced Nursing, 34(4), 520-529. doi:10.1046/j.1365-2648.2001.01781.x

Brown, N., Melville, M., Gray, D., Young, T., Munro, J., Skene, A. M., \& Hampton, J. R. (1999). Quality of life four years after acute myocardial infarction: Short form 36 scores compared with normal population. Heart, 81(4), 352-258.

doi:http://dx.doi.org/10.1136/hrt.81.4.352

Buysse, D. J., Germain, A., Moul, D. E., Franzen, P. L., Brar, L. K., Fletcher, M. E., ..., \& Monk, T. H. (2011). Efficacy of brief behavioral treatment for chronic insomnia in older adults. Archives of Internal Medicine, 171(10), 887-895.

doi:10.1001/archinternmed.2010.535

Buysse, D. J., Rush, A. J., \& Reynolds, C. F. $3^{\text {rd }}$. (2017). Clinical management of insomnia disorder. Journal of the American Medical Association, 318(20), 1973-1974. doi:10.1001/jama.2017.15683

Campbell, S. S., Gillin, J. C., Kripke, D. F., Erikson, P., \& Clopton, P. (1989). Gender differences in the circadian temperature rhythms of healthy elderly subjects: Relationships to sleep quality. Sleep, 12(6), 529-536. doi:https://doi.org/10.1093/sleep/12.6.529 
Canivet, C., Nilsson, P. M., Lindeberg, S. I., Karasek, R., \& Östergren, P-O. (2014). Insomnia increases risk for cardiovascular events in women and in men with low socioeconomic status: A longitudinal, register-based study. Journal of Psychosomatic Research, 76(4), 292-299. doi:10.1016/j.jpsychores.2014.02.001

Cardiac Care Network [CCN]. (2014). Standards for the provision of cardiovascular rehabilitation in Ontario: September 2014. Retrieved from https://www.corhealthontario.ca/resources-for-healthcare-planners- \&providers/rehabilitation/CCN_Cardiovascular_Rehab_Standards_2014.pdf

Carney, C. E., Buysse, D. J., Ancoli-Israel, S., Edinger, J. D., Krystal., A. D., Lichstein, K. L., \& Morin, C. M. (2012). The Consensus Sleep Diary: Standardizing prospective sleep selfmonitoring. Sleep, 35(2), 287-302. doi:10.5665/sleep.1642

Chakravorty, S., Siu, H. Y. K., Lalley-Chareczko, L., Brown, G. K., Findley, J. C., Perlis, M. L. \& Grandner, M. A. (2015). Sleep duration and insomnia symptoms as risk factors for suicide ideation in a nationally representative sample. The Primary Care Companion for CNS Disorders, 17(6), 1-9. doi:10.4088/PCC.13m01551

Chaput, J-P., Wong, S. L., \& Michaud, I. (2017). Duration and quality of sleep among Canadians aged 18 to 79. Statistics Canada. Retrieved from http://www.statcan.gc.ca/pub/82-003x/2017009/article/54857-eng.htm

Chung, K-F., Kan, K. K-K., \& Yeung, W-F. (2011). Assessing insomnia in adolescents: Comparison of Insomnia Severity Index, Athens Insomnia Scale, and Sleep Quality Index. Sleep Medicine, 12(5), 463-470. doi:10.1016/j.sleep.2010.09.019 
Ciano, C., King, T. S., Wright, R. R., Perlis, M., \& Sawyer, A. M. (2017). Longitudinal study of insomnia symptoms among women during perimenopause. Journal of Obstetric, Gynecological \& Neonatal Nursing, 46(6), 804-813. doi:10.1016/j.jogn.2017.07.011

Cohen, J. W. (1988). Statistical power analysis for the behavioral sciences ( $2^{\text {nd }}$ ed.). Hillsdale, NJ: Lawrence Erlbaum Associates.

Crowley, K. (2011). Sleep and sleep disorders in older adults. Neuropsychology Review, 21(1), 41-53. doi:10.1007/s11065-010-9154-6

Derogatis, L. R. (1997). The Symptom Checklist-90- Revised. Minneapolis, MN: NCS Assessments.

DeVon, H. A, Pettey, C. M., Vuckovic, K. M., Koenig, M. D., \& McSweeney, J. C. (2016). A review of the literature on cardiac symptoms in older and younger women. JOGNN, 45(3), 426-437. Retrieved from https://journals-scholarsportalinfo.ezproxy.lib.ryerson.ca/pdf/08842175/v45i0003/426_arotlosioayw.xml

Drager, L. F., Bortolotto, L. A., Lorenzi, M. C., Figueiredo, A. C., Krieger, E. M., \& LorenziFilho, G. (2005). Early signs of atherosclerosis in obstructive sleep apnea. American Journal of Respiratory and Critical Care Medicine, 172(5), 613-618. doi:10.1164/rccm.200503-3400C

Edéll-Gustaffson, U. M. (2002). Insufficient sleep, cognitive anxiety and health transition in men with coronary artery disease: A self-report and polysomnographic study. Journal of Advanced Nursing, 37(5), 414-422. doi:10.1046/j.1365-2648.2002.02106.x 
Eiman, M. N., Weinstein, A. A., \& Kop, W. J. (2017). Relationship of sleep efficiency to cognitive performance and cardiovascular response to cold challenge. Sleep, 40(1), A79. doi:10.1093/sleepj/zsx050.213

Fang, J., \& Bjorkman, D. (2001). A critical approach to noncardiac chest pain: Pathophysiology, diagnosis, and treatment. The American Journal of Gastroenterology, 96(4), 958-968. doi:10.1111/j.1572-0241.2001.03678.x

Fernandez-Mendoza, J., Vgontzas, A. N., \& Liao, D. (2012). Insomnia with objective short sleep duration and incident hypertension: The Penn State Cohort. Hypertension, 60, 929-935. doi:https://doi.org/10.1161/HYPERTENSIONAHA.112.193268

Folstein, M. F., Folstein, S.E., \& McHugh, P. R. (1975). "Mini-mental state.” A practical method for grading the cognitive state of patients for the clinician. Journal of Psychiatric Research, 12(3), 189-198. doi:10.1016/0022-3956(75)90026-6

Fox-Wasylyshyn, S. M., \& El-Masri, M. M. (2005). Handling missing data in self-report measures. Research in Nursing and Health, 28(6), 488-495. doi:10.1002/nur.20100

Fredericks, S., Sidani, S., Miranda, J., \& Fox, M. (2016). Examining cardiovascular symptoms in adults living with chronic insomnia. British Journal of Cardiac Nursing, 11(9), 430-436. doi:10.12968/bjca.2016.11.9.430

Gallagher, R., Marshall, A. P., \& Fisher, M. J. (2010). Symptoms and treatment-seeking responses in women experiencing acute coronary syndrome for the first time. Heart \& Lung: The Journal of Acute and Critical Care, 39(6), 477-484. Retrieved from http://www.sciencedirect.com.ezproxy.lib.ryerson.ca/science/article/pii/S01479563090027 14?via\%3Dihub 
Garland, S. N., Rowe, H., Repa, L. M., Lily, M., Fowler, K., Zhou, E. S., \& Grandner, M. A. (2018). A decade's difference: 10-year change in insomnia symptom prevalence in Canada depends on sociodemographics and health status. Sleep Health, 4(2), 160-165. doi:10.1016/j.sleh.2018.01.003

Gellis, L. A., Lichstein, K. L., Scarinci, I. C., Durrence, H. H., Taylor, D. J., \& Bush, A. J. (2005). Socioeconomic status and insomnia. Journal of Abnormal Psychology, 114(1), 111-118. doi:10.1037/0021-843X.114.1.111

Gray, J., Grove, S. \& Sutherland, S. (2017). Burns and Groves's the practice of nursing research: Appraisal, synthesis and generation of evidence ( $8^{\text {th }}$ ed). St. Louis: Elsevier.

Green, S. B., \& Salkind, N., J. (2008). Using SPSS for windows and macintosh: Analyzing and understanding data (5 $5^{\text {th }}$ ed.). Upper Saddle River, NJ: Pearson/Prentice Hall.

Grubb, N. R. (2002). Cardiac symptoms. Medicine, 30(3), 1-4. Retrieved from https://journalsscholarsportal-info.ezproxy.lib.ryerson.ca/pdf/13573039/v30i0003/1_cs.xml

Gulia, K. K., \& Kumar, V. M. (2018). Sleep disorders in the elderly: A growing challenge. Psychogeriatrics, 18, 155-165. doi:10.1111/psyg.12319

Hacksaw, A. (2008). Small studies: Strengths and limitations. European Respiratory Journal, 32, 1141-1143. doi:10.1183/09031936.00136408

Ham, O. K., Kim, J., Lee, B. G., \& Choi, E. (2017). Behavioral characteristics and cardiovascular disease risks associated with insomnia and sleep quality among middleaged women in South Korea. Research in Nursing and Health, 40(3), 206-217. doi:10.1002/nur.21792 
Hannon, R. A., Pooler, C., Porth, C. M. (2010). Porth pathophysiology: Concepts of altered health states. Philadelphia, PA: Lippincott Williams \& Wilkins.

Havlicek, L. L., \& Peterson, N. L. (1977). Effect of the violation of assumptions upon significance levels of the Pearson r. Psychological Bulletin, 84(2), 373-377. doi:10.1037/0033-2909.84.2.373

Hayley, A. C., Williams, L. J., Venugopal, K., Kennedy, G. A., Berk, M., \& Pasco, J. A. (2015). The relationship between insomnia, sleep apnoea and depression: Findings from the American National Health and Nutrition Examination Survey, 2005-2008. Australian \& New Zealand Journal of Psychiatry, 49(2), 156-170. doi:10.1177/0004867414546700

Hertzog, M. A. (2008). Considerations in determining sample size for pilot studies. Research in Nursing and Health, 31(2), 180-191. doi:10.1002/nur.20247

Hoevenaar-Blom, M. P., Spijkerman, A. M. W., Kromhout, D., van den Berg, J. F., \& Verschuren, W. M. M. (2011). Sleep duration and sleep quality in relation to 12-year cardiovascular disease incidence: The MORGEN study. Sleep, 34(11), 1487-1492. doi:https://doi.org/10.5665/sleep.1382

Husser, D., Bollmann, A., Kühne, C., Molling, J., \& Klein, H. U. (2012). Evaluation of noncardiac chest pain: Diagnostic approach, coping strategies and quality of life. European Journal of Pain, 10(1), 51-55. doi:10.1016/j.ejpain.2005.01.011

Jackson, C. L., Redline, S., \& Emmons, K. M. (2015). Sleep as a potential fundamental contributor to disparities in cardiovascular health. Annual Review of Public Health, 36, 417-440. doi:10.1146/annurev-publhealth-031914-122838 
Javaheri, S. \& Redline, S. (2017). Insomnia and risk of cardiovascular disease. Chest, 152(2), 435-444. doi:http://dx.doi.org/10.1016/j.chest.2017.01.026

Johansson, P., Arestedt, K., Alehagen, U., Svanborg, E., Dahlstrom, U., \& Brostrom, A. (2010). Sleep disordered breathing, insomnia, and health related quality of life - a comparison between age and gender matched elderly with heart failure or without cardiovascular disease. European Journal of Cardiovascular Nursing, 9, 108-117. doi:10.1016/j.ejcnurse.2009.11.005

Johns, M. W. (1991). A new method for measuring daytime sleepiness: The Epworth Sleepiness Scale. Sleep, 14(6), 540-545. doi:https://doi.org/10.1093/sleep/14.6.540

Johns, M. W. (1992). Reliability and factor analysis of the Epworth Sleepiness Scale. Sleep, 15(4), 376-381. doi:https://doi.org/10.1093/sleep/15.4.376

Johnson, B. D., Shawm L. J., Pepine, C. J., Reis, S. E., Kelsey, S. F., Sopko, G., ... Bairey Merz, C. N. (2006). Persistent chest pain predicts cardiovascular events in women without obstructive coronary artery disease: Results from the NIH-NHLBI-sponsored Women's Ischaemia Syndrome Evaluation (WISE) study. European Heart Journal, 27(12), 14081415. doi:https://doi.org/10.1093/eurheartj/eh1040

Kasper, E. K., \& Knudson, M. (2010). Living well with heart failure, the misnamed, misunderstood condition. Baltimore, MD: Johns Hopkins University Press

Ketterer, M. W., Knysz, W., Keteyian, S. J., Schairer, J., Jafri, S., Alam, M., . . Deveshwar, S. (2008). Cardiovascular symptoms in coronary-artery disease patients are strongly 
correlated with emotional distress. Psychosomatics, 49(3), 230-234.

doi:10.1176/appi.psy.49.3.230

Khambhati, J., Allard-Ratick, M., Dhindsa, D., Lee, S., Chen, J., Sandesara, P. B., ... \& Sperling, L. S. (2018). The art of cardiovascular risk assessment. Clinical Cardiology, 41(5), 677-684. doi:10.1002/clc.22930

King, C. R., Knutson, K. L., Rathouz, P. J., Sidney, S., Liu, K., \& Lauderdale, D. S. (2008). Short sleep duration and incident coronary artery calcification. JAMA, 300(24), 2859-2866. doi:10.1001/jama.2008.867

Kreatsoulas, C., Shannon, H. S., \& Giacomini, M. (2013) Reconstructing angina: Cardiac symptoms are the same in women and men. Journal of American Medical Association Internal Medicine, 173(9), 829-833. Retrieved from https://jamanetwork.com/journals/jamainternalmedicine/fullarticle/1675875

Laugsand, L. E., Strand, L. B., Platou, C., Vatten, L. J., \& Janszky, I. (2014). Insomnia and the risk of incident heart failure: A population study. European Heart Journal, 35, 1382-1393. doi:https://doi.org/10.1093/eurheartj/eht019

Laugsand, L. E., Strand, L. B., Vatten, L. J., Janszky, I., \& Bjørngaard, J. H. (2014). Insomnia symptoms and risk for unintentional fatal injuries -- the HUNT Study. Sleep, 37(11), $1777-$ 1786. doi:https://doi.org/10.5665/sleep.4170

Laugsand, L. E., Vatten, L., J., Platou, C., \& Janszky, I. (2011). Insomnia and the risk of acute myocardial infarction: A population study. Circulation, 124(19), 2073-2081. doi:https://doi.org/10.1161/CIRCULATIONAHA.111.025858 
LeBlanc, M., Beaulieu-Bonneau, S., Mérette, C., Savard, J., Ivers, H., \& Morin, M. (2007). Psychological and health-related quality of life factors associated with insomnia in a population-based sample. Journal of Psychosomatic Research, 63(2), 157-166. doi:10.1016/j.jpsychores.2007.03.004

Lee, S., Almeida, D. M., Berkman, L., Olson, R., Moen, R., \& Buxton, O. M. (2016). Age differences in workplace intervention effects on employees' nighttime and daytime sleep. Sleep Health, 2(4), 289-296. doi:10.1016/j.sleh.2016.08.004

Lewis, S. M, Barry, M., Goldsworthy, S., \& Goodridge, D. (2010). Medical-surgical nursing in Canada: Assessment and management of clinical problems ( $2^{\text {nd }}$ ed.). Toronto: Elsevier.

Li, M., Zhang, X-W., Hou, W-S., \& Tang, Z-Y. (2014). Insomnia and risk of cardiovascular disease: A meta-analysis of cohort studies. International Journal of Cardiology, 176, 10441047. doi:http://dx.doi.org/10.1016/j.ijcard.2014.07.284

Li, Y., Zhang, X., Winkelman, J. W., Redline, S., Hu, F. B., Stampfer, M., Ma, J., \& Gao, X. (2014). Association between insomnia symptoms and mortality: A prospective study of U.S. men. Circulation, 129(7), 737-746. doi:https://doi.org/10.1161/CIRCULATIONAHA.113.004500

Mallon, L., Broman, J. E., \& Hetta, J. (2002). Sleep complaints predict coronary artery disease mortality in males: A 12-year follow-up study of a middle-aged Swedish population. Journal of Internal Medicine, 251(3), 207-216. doi:10.1046/j.1365-2796.2002.00941.x

Maness, D. L., \& Khan, M. (2015). Nonpharmacological management of chronic insomnia. American Family Physician, 92(12), 1058-1064. Retrieved from https://www.aafp.org/afp/2015/1215/p1058.pdf 
Mansen, T. J., \& Gabiola, J. (2015). Patient-focused assessment: The art and science of clinical data gathering. Upper Saddle River, NJ: Pearson

Marin, J. M., Carrizo, S. J., Vincente, E. \& Augusti, A. G. (2005). Long-term cardiovascular outcomes in men with obstructive sleep apnoea-hypopnoea with or without treatment with continuous positive airway pressure: An observational study. Lancet, 365(9464), 10461053. doi:10.1016/S0140-6736(05)71141-7

Meisinger, C., Heier, M., Lowel, H., Schneider, A., Doring, A. (2007). Sleep duration and sleep complaints and risk of myocardial infarction in middle-aged men and women from the general population: the MONICA/KORA Augsburg cohort study. Sleep, 30(9), 1121-1127. doi:https://doi.org/10.1093/sleep/30.9.1121

Medalie, L. \& Cifu, A. S. (2017). Management of chronic insomnia disorder in adults. Journal of the American Medical Association, 317(7), 762-763. doi:10.1001/jama.2016.19004

Miranda, J., Sidani, S., Fredericks, S., \& Fox, M. (2017). Sleep and cardiovascular effects of behavioural therapies for insomnia. British Journal of Cardiac Nursing, 12(10), 488-495. doi:https://doi.org/10.12968/bjca.2017.12.10.488

Morin, C. M. (1993). Insomnia: Psychological assessment and management. New York: Guilford Press.

Morin, C. M., Belleville, G., Belanger, L., \& Ivers, H. (2011). The Insomnia Severity Index: Psychometric indicators to detect insomnia cases and evaluate treatment response. Sleep, 34(5), 601-608. doi:https://doi.org/10.1093/sleep/34.5.601 
Morin, C. M., Vallières, A., Guay, B., Ivers, H., Savard, J., Mérette, C., ... Baillargeon, L. (2009). Cognitive behavioral therapy, singly and combined with medication, for persistent insomnia: A randomized controlled trial. Journal of American Medical Association, 301(19), 2005-2015. doi:10.1001/jama.2009.682

Newman, D. A. (2014). Missing data: Five practical guidelines. Organizational Research Methods, 17(4), 372-411. doi:10.1177/1094428114548590

Pallant, J. (2013). SPSS survival manual (5 ${ }^{\text {th }}$ ed.). New York, NY: McGraw-Hill.

Phillips, B., \& Mannino, D. (2007). Do insomnia complaints cause hypertension or cardiovascular disease? Journal of Clinical Sleep Medicine, 3(5), 489-494. Retrieved from https://www.ncbi.nlm.nih.gov/pmc/articles/PMC1978336/pdf/jcsm.3.5.489.pdf

Public Health Agency of Canada. (2009). Tracking Heart Disease and Stroke in Canada: 2009. Retrieved from http://books2.scholarsportal.info.ezproxy.lib.ryerson.ca/viewdoc.html?id=/ebooks/ebook s1/gibson_chrc/2010-08-06/5/10309427\#tabview=tab1

Redeker, N. S., Jeon, S., Muench, U., Campbell, D., Walsleben, J., \& Rapoport, D. M. (2010). Insomnia symptoms and daytime function in stable heart failure. Sleep, 33(9), 12101216. doi:https://doi.org/10.1093/sleep/33.9.1210

Rediehs, M. H., Reis, J. S., \& Creason, N. S. (1990). Sleep in old age: focus on gender differences. Sleep 13(5), 410-424. doi:https://doi.org/10.1093/sleep/13.5.410

Rials, S. J., Hatlestad, J. D., Smith, A., Pubbi, D., Slotwiner, D. J., \& Boehmer, J. P. (2017). Night-time elevation angle in heart failure patients indicates orthopnea and paroxysmal 
nocturnal dyspnea. Journal of Cardiac Failure, 23(8), S81.

doi:10.1016/j.cardfail.2017.07.232

Rose, M. S., Koshman, M. L., Spreng, S. \& Sheldon, R. (2000). The relationship between healthrelated quality of life and frequency of spells in patients with syncope. Journal of Clinical Epidemiology, 53(12), 1209-1216. doi:10.1016/S0895-4356(00)00257-2

Ryan, C. J., DeVon, H. A., Zerwic, J. J. (2005). Typical and atypical symptoms: Diagnosing acute coronary syndromes accurately. American Journal of Nursing, 105(2), 34-36.

Retrieved from http://ovidsp.uk.ovid.com.ezproxy.lib.ryerson.ca/sp-

3.27.1a/ovidweb.cgi?\&S=MDKAPDCPLBHFLANPFNGKPGAGPNNBAA00\&Link+Set $=$ S.sh.22.23.26.29\%7c23\%7csl_10

Sands-Lincoln, M., Loucks, E. B., Lu, B., Carskadon, M. A., Sharkey, K., Stefanick, M. L., ... Eaton, C. B. (2013). Sleep duration, insomnia, and coronary heart disease among postmenopausal women in the women's health initiative. Journal of Women's Health, 22(6), 477-486. doi:10.1089/jwh.2012.3918

Schutte-Rodin, S., Broch, L., Buysse, D., Dorsey, C., \& Sateia. (2008). Clinical guideline for the evaluation and management of chronic insomnia in adults. Journal of Clinical Sleep Medicine, 4(5), 487-504.

Shafique, N., Khalily, M. T., \& McHugh, L. (2017). Translation and validation of Symptom Checklist-90. Pakistan Journal of Psychological Research, 32(2), 545-561. Retrieved from https://search-proquest-com.ezproxy.lib.ryerson.ca/docview/1992199657?pqorigsite=summon 
Shahly, V., Berglund, P. A., \& Coulouvrat, C. (2012). The associations of insomnia with costly workplace accidents and errors: Results from the America Insomnia Survey. Archives of General Psychiatry, 69(10), 1054-1063. doi:10.1001/archgenpsychiatry.2011.2188

Sidani, S., Ibrahim, S., Lok, J., O’Rourke, H., Collins, L., \& Fox, M. (2018). Comparing the experience of and factors perpetuating chronic insomnia severity among young, middleaged, and older adults. Clinical Nursing Research, $0(0), 1-24$. doi: $10.1177 / 1054773818806164$

Social Sciences Statistics. (2019). Effect size calculator for t-test. Retrieved from https://www.socscistatistics.com/effectsize/default3.aspx

Sofi, F., Cesari, F., Casini, A., Macchi, C., Abbate, R., \& Gensini, G. F. (2012). Insomnia and risk of cardiovascular disease: A meta-analysis. European Journal of Preventive Cardiology, 21(1), 57-64. doi:10.1177/2047487312460020

Sorscher, A. J. (2017). Insomnia: Getting to the cause, facilitating relief. Journal of Family Practice, 66(4), 216-225. Retrieved from https://www.mdedge.com/sites/default/files/JFP06604216.PDF

Statistics Canada. (2017). Table 102-0561 - Leading causes of death, total population, by age group and sex, Canada, annual [Data file]. Retrieved from http://www5.statcan.gc.ca/cansim/a05?lang=eng\&id=1020561

Strand, L. B., Tsai, M. K., Gunnell, D., Janszky, I., Wen, C. P., Chang, S. S. (2016). Selfreported sleep duration and coronary heart disease mortality: A large cohort study of 400,000 Taiwanese adults. International Journal of Cardiology, 207(), 246-251. doi:10.1016/j.ijcard.2016.01.044 
Sun, B. C. (2013). Quality-of-life, health service use, and costs associated with syncope. Progress in Cardiovascular Diseases, 55(4), 370-375. doi:10.1016/j.pcad.2012.10.009

Sutton, D. A., Moldofsky, H., \& Badley, E. M. (2001). Insomnia and health problems in Canadians. Sleep, 24(6), 665-670. doi:https://doi.org/10.1093/sleep/24.6.665

Taylor, K., Bilan, N., Tsytsyna, N., \& Mandel, E. D. (2017). A nonpharmacological approach to managing insomnia in primary care. Journal of the American Academy of Physician Assistants, 30(11), 10-15. doi:10.1097/01.JAA.0000525905.52107.20

Taylor, D. J., Mallory, L. J., Lichstein, K. L., Durrence, H. H., Riedel, B. W., \& Bush, A. J. (2007). Comorbidity of chronic insomnia with medical problems. Sleep, 30(2), 213-218. doi:https://doi.org/10.1093/sleep/30.2.213

Ten Voorde, M., van der Zaag-Loonen, H. J., \& van Leeuwen, R. B. (2012). Dizziness impairs health-related quality of life. Quality of Life Research, 21(6), 961-966. doi:10.1007/s11136-011-0001-x

Tessaro, M., \& Navarro-Peternella, F. M. (2015). Sleeping effects in the quality of life of women with insomnia. Fisioterapia em Movimento, 28(4), 693-700. doi:http://dx.doi.org/10.1590/0103-5150.028.004.AO06

Thase, M. E. (2005). Correlates and consequences of chronic insomnia. General Hospital Psychiatry, 27(2), 100-112. doi:10.1016/j.genhosppsych.2004.09.006

Volpe, M., Chin, D., \& Paneni, F. (2010). The challenge of polypharmacy in cardiovascular medicine. Fundamental and Clinical Pharmacology, 24(1), 9-17. doi:10.1111/j.14728206.2009.00757.x 
Wade, A., \& Downie, S. (2008). Prolonged-release melatonin for the treatment of insomnia in patients over 55 years. Expert Opinion on Investigational Drugs, 17(10), 1567-1572. doi:10.1517/13543784.17.10.1567

Wikman, A., Messerli-Bürgy, N., Molloy, G. J., Randall, G., Perkins-Porras, L., \& Steptoe, A. (2012). Symptom experience during acute coronary syndrome and the development of posttraumatic stress symptoms. Journal of Behavioral Medicine, 35(4), 410-430. Retrieved from https://journals-scholarsportalinfo.ezproxy.lib.ryerson.ca/details/01607715/v35i0004/420_sedacstdopss.xml

Winkelman, J. W. (2015). Clinical practice. Insomnia disorder. New England Journal of Medicine, 373(15), 1437-1444. doi:10.1056/NEJMcp1412740 